\title{
FLOCCULATION AND REDISPERSION OF CELLULOSIC FIBER SUSPENSIONS: A REVIEW OF EFFECTS OF HYDRODYNAMIC SHEAR AND POLYELECTROLYTES
}

\author{
Martin A. Hubbe \\ Cellulosic fibers in aqueous suspensions are subject to flocculation \\ effects that involve two contrasting scales of dimension. The net effect \\ of flocculation determines how uniformly fibers can become formed into a \\ sheet during the manufacture of paper. At a macroscopic level, the \\ highly elongated shape of typical wood-derived fibers in agitated sus- \\ pensions can give rise to frequent inter-fiber collisions and the formation \\ of fiber flocs. At a submicroscopic scale, surfaces of suspended \\ materials can become joined by macromolecular bridges. Although such \\ bridges tend to reduce paper's uniformity, polyelectrolyte flocculants are \\ used in most paper machine systems to achieve relatively high retention \\ efficiencies of fine particles as paper is being formed. By adjusting the \\ papermaking equipment, judiciously selecting points of addition of \\ chemicals, and by managing chemical dosages, papermakers employ a \\ variety of strategies to achieve favorable combinations of retention and \\ uniformity. This review considers scholarly work that has been directed \\ towards a greater understanding of the underlying mechanisms.
}

Keywords: Flocculation, Cellulose, Fibers, Pulp, Suspensions, Polyelectrolytes, Hydrodynamic shear, Paper formation, Retention aids, Uniformity, Crowding, Selective detachment

Contact information: Department of Forest Biomaterials Science and Engineering, North Carolina State University, Campus Box 8005, Raleigh, NC 27695-8005 USA; hubbe@ncsu.edu

\section{INTRODUCTION}

The subject of flocculation of cellulosic fibers in aqueous suspensions is both fascinating and economically important. Certain aspects of the process have been called "paradoxical" (see Hubbe and Rojas 2005). Fiber flocculation appears to depend on phenomena occurring within two markedly different ranges of size. At a molecular scale, suspensions of cellulosic materials and fine particles are affected by short-range electrostatic, dispersion, and polymer bridging forces acting between surfaces. At a macroscopic scale, cellulosic fibers are sufficiently long, relative to their thickness, so that they tend to collide with each other in stirred suspensions. Though agitation also can play a role in separating fibers from one another, the distribution of cellulosic fibers in an agitated suspension is typically less uniformly distributed in space, compared to what would be predicted by a random number generator.

The term "flocculation" can be defined differently in each of the two size regimes just mentioned. At a molecular scale, where the focus is on the interactions between objects within about $100 \mathrm{~nm}$ of each other, "flocculation" can refer to the role of highmolecular-mass polyelectrolytes in forming bridges between surfaces. In this article the 
word "colloidal" also will be used to refer to events occurring at a scale of nanometers. The words "agglomeration," and "deposition" will be used to refer to solid objects coming and remaining in contact, regardless of the cause. The word "coagulation" will be used to describe the effects of water-soluble chemicals such as aluminum sulfate or low-mass polyelectrolytes, which can bring about agglomeration as a result of charge neutralization or by means of localized electrostatic effects (Hogg et al. 1966; Hunter 1987). The term "flocculation," when it is used in reference to chemical effects, is usually reserved to describe the action of high-mass polyelectrolytes that can form strong bridges between surfaces (La Mer and Healy 1963; Gregory 1973, 1976). As will be described in greater detail, such bridges appear to break irreversibly, if the suspension encounters hydrodynamic forces of sufficient intensity and duration.

At a macroscopic scale the term "flocculation" can be used as a synonym for "the formation of clumps of fibers," regardless of the cause. As will become clear in the course of this review, macro-scale flocculation can occur for mechanical and hydrodynamic reasons, even if there is a net repulsion between the surfaces at a colloidal scale. Chemical treatments often can make macroscopic flocculation more intense than it would have been otherwise. This is especially true in the case of "flocculants" or "retention aids," which are other names used for the very-high-mass polyelectrolytes capable of forming macromolecular bridges.

\section{Why Papermakers Care}

Papermaking technologists have economic and practical reasons to be interested in flocculation. During conventional paper production, as well as during production of wet-laid non-woven fabrics, the papermaker attempts to avoid excessive flocculation or entanglement of the fibers (Rojas and Hubbe 2004). Paper that contains a lot of thick areas, due to the presence of flocs, also must contain a lot of thin, weak areas, adjacent to those flocs. Correlations between paper's strength and its uniformity have been predicted or shown in various studies (Linhart et al. 1987; Waterhouse 1993; Korteoja et al. 1997, 1998; Nazhad et al. 2000). Nonuniform paper also can hurt paper's appearance and adversely affect subsequent operations, such as coating (Hua et al. 1996). Various methods have been developed to quantify paper's uniformity (Norman and Wahren 1972; Peters 1997; Keller and Pawlak 2001; Bernié and Douglas 2001).

At the same time that papermakers are attempting to produce highly uniform paper, they also have a strong incentive to maintain a high efficiency of retention of fine particles. Such particles can include mineral "fillers," which often make up 10-25\% of the mass of paper intended for printing. The diameters of typical filler particles lie in the range of about 0.25 to $5 \mu \mathrm{m}$, a size that is much too small to be retained by filtration by the forming fabrics used in paper manufacture (Van de Ven 1984). Other small particles in papermaking furnish can include fiber fines (e.g. parenchyma cells), and emulsion particles used for hydrophobizing or "internal sizing" of the paper. The chemical efficiency of such sizing agents can fall significantly if they are not retained during the first pass through the forming section of a paper machine. Unretained sizing agents can spend several additional minutes in contact with the aqueous solution or "white water" used in papermaking, causing the chemicals to become hydrolyzed (Savolainen 1996). In addition, non-retained fine materials can be wasteful, contributing to costs of wastewater 
treatment and sludge disposal, as well as contributing to deposits that form on the wetted surfaces of process equipment.

The most common strategies used by papermakers to retain fine particle at high efficiency all involve very-high-mass polyelectrolytes, i.e. "retention aids" (Allen and Yaraskavitch 1989; Horn and Linhart 1991; Swerin and Ödberg 1997; Alfano et al. 1998; Norell et al. 1999; Tripattharanan et al. 2004a). The most commonly used retention aids consist of water-soluble cationic or anionic copolymers of acrylamide, having mean molecular masses in the range of about 4 million to 20 million Daltons. Use of such polymers can cause significant decreases in paper's uniformity, especially at excessively high retention aid dosages or when hydrodynamic shear forces are inadequate to break up the resulting flocs (Lindström et al. 1977; Jokinen and Ebeling 1985; Jokinen and Palonen 1986; Eisenlauer et al. 1987; Wågberg and Lindström 1987ab; Adamski et al. 1991; Horn and Linhart 1991; Swerin and Ödberg 1993, 1997; Swerin et al. 1996a; Swerin et al. 1997; Swerin 1998; Alfano et al. 1998; Clemençon and Gerli 2000; Hubbe 2000; Gruber and Müller 2001; Anker 2002; Solberg and Wågberg 2003). Chemicallyinduced increases in flocculation also tend to reduce the strength of the resulting paper (Roberts et al. 1986, 1987; Linhart et al. 1987).

An order-of-magnitude estimate can be made of the economic loss that results from paper's nonuniformity (see Hubbe 2005a). Nazhad et al. (2000) prepared laboratory sheets of paper having different uniformity. Uniformity was evaluated in terms rootmean-squared variations in basis weight of small areas, and compared to the tensile force required for breakage. By comparing their laboratory results to typical machine-made papers, it can be estimated that there is potential to achieve about $30 \%$ higher strength, if only the sheets were more uniform. According to Dodson and Serafino (1993), the variation of local basis weight of typical machine-made paper, on a scale of $1 \mathrm{~mm}$, is about twice what would be obtained if the fiber had been laid in random positions. Using a more conservative number, let's suppose that it were possible to improve formation to such a degree that it was possible to reduce the basis weight of paper by $10 \%$ in a typical case. Since worldwide paper sales are in the neighborhood of 200 billion dollars per year, and because materials can make up a substantial part of the cost of paper (Diesen 1998), it follows that the annual value of improved formation might be in the range of 1020 billion dollars.

\section{A Working Hypothesis}

The goals of this review can be stated in the form of a hypothesis, as follows: It is proposed that papermakers' success in meeting their goals within both size ranges of flocculation - molecular and macroscopic - requires optimization of sequential events. These events are affected by polyelectrolyte interactions, the ionic charges on various macromolecules and surfaces, hydrodynamic shear, and the effects of time. Though it is possible for paper technologists to optimize such parameters in an evolutionary manner, through incremental adjustments, a goal of this review is to show that the net results can be explained in mechanistic terms.

A second hypothesis will be proposed in order to answer the question, "In light of the complexity of papermaking systems, why have papermakers usually been quite successful in achieving favorable combinations of efficient fine-particle retention and 
uniform formation?" The following two-part explanation will be supported by the literature:

1. Chemically-induced attachments between fibers can be broken at much lower levels of hydrodynamic shear stress compared to similar attachments of fine particles to fiber surface.

2. Attachments resulting from very-high-mass polyelectrolytes typically are somewhat irreversible, not capable of being formed again with the same strength after breakable of the initial contact.

Before evaluating the two hypotheses, as just given, one needs to understand something about the solid materials, the unit operations through which the fibers pass during the manufacture of paper, and various ways that fiber suspensions are affected by flow. These issues are considered in the following two sections.

\section{CELLULOSE FIBER SUSPENSIONS - A PAPERMAKER'S PERSPECTIVE}

\section{Fibers from Wood}

From a historical perspective the statement that "paper is made from trees" reflects relatively recent developments. Prior to 1775 most fibers used for papermaking originated from such sources as cotton, linen, or bark (Hunter 1947). To save costs, papermakers often used recycled textile fibers, i.e. rags. Rags continued to be a dominant source of papermaking fibers until about 1860, when wood pulp began to displace the dwindling rag supply. Advantages of wood as a fiber source for paper include its abundant supply, year-round availability, relatively high density, good storage stability, relative uniformity, and favorable ratio of fiber length to thickness. Issues related to the length-to-thickness ratio will be considered in a later section of this review.

Ways in which cellulosic fibers are separated from wood can play a significant role with respect to flocculation. Two main approaches, mechanical pulping and chemical pulping, are used to convert wood into its component fibers. Mechanical pulping most often involves abrading fibers from wood chips in the presence of water. The process is called "refining" when it takes place between the surfaces of steel plates, one of which is rotating (Smook 1992; Baker 1995). Raised rectangular bars on the plates squeeze and shear the woody material, causing fibers to separate. Considerable damage to the fibers occurs during mechanical pulping, yielding a broad range of sizes in the resulting suspension.

In an effort to preserve more of the initial fiber length of fibers, as was present originally in the wood, much of the mechanical pulping nowadays is done at raised temperatures. By carrying out the refining operation under pressure in the presence of steam, during so-called "thermo-mechanical pulping" (TMP), the lignin that holds fibers together in wood becomes softened (Back and Salmén 1982; Salmén et al. 1985), and the fibers can be separated with less shortening. Advantages of mechanical fibers, from a papermaker's standpoint, include their high yield, retaining over $90 \%$ of the solid material from wood chips. Disadvantages include a high requirement of electrical energy, relatively poor brightness stability, and limited strength characteristics. Factors 
that limit the strength of paper made from TMP fibers include their relative nonconformability, shortened fiber length, and the presence of hydrophobic materials on the fiber surfaces. Fatty acids and esters, rosin acids (in the case of softwood fibers), and various unsaponifiable oils from wood are known to interfere with the development of hydrogen bonds between fibers when paper is dried.

Chemical pulping of wood chips, especially by means of the kraft process, has become the leading source of fibers for papermaking. From the standpoint of flocculation, some distinguishing characteristics of kraft fibers, relative to TMP fibers, include greater preservation of fiber length, less debris, greater flexibility (especially after refining), and a more hydrophilic surface. Tam Doo and Kerekes (1982) observed that chemical pulp fibers were 20 to 30 times more flexible that mechanical pulp fibers from the same wood source. The sodium hydroxide and sodium sulfide used in a kraft cook tend to solubilize lignin, the phenolic glue that holds fibers together in wood. Most of the extractable, relatively hydrophobic components of wood are likewise removed, partly by saponification and partly in the formation of soap-stabilized emulsion droplets. Subsequent multi-stage bleaching of kraft fibers with such materials as chlorine dioxide, oxygen, ozone, and hydrogen peroxide, usually with at least one alkaline extraction stage and several washing operations, results in a purification of the fibers, leaving behind mainly the relatively hydrophilic polysaccharide components of the fiber. Despite the removal of carboxylic acid species during kraft pulping and various types of bleaching operations, cellulosic fibers upon their arrival at paper mills typically still have a weak negative charge when they are placed in water (Herrington and Petzold 1992; Lloyd and Horne 1993).

To achieve an optimum balance of the paper's strength, apparent density, and appearance characteristics, kraft fibers are subjected to different levels of refining after the pulping process is completed. The mechanical compression and shearing of kraft fibers in a refiner results in internal delamination, making the fibers more flexible (Paavilainen 1993). Whereas the cross-section of an unrefined kraft fiber often can be described as rectangular or "rounded," refining allows the fibers to collapse into a ribbonlike form. A broad contact between fibers in paper yields greater density and higher strength.

Fiber length is a key factor related to fiber flocculation (see next section). Refining can affect fiber length in two ways. First, refining sometimes straightens bent or kinked fibers, increasing their end-to-end distance ( $\mathrm{Ny}$ and Messmer 2004). The effect can be compared to the straightening that occurs when a long balloon becomes filled with air. However, unlike such a balloon, fibers remain relatively constant in length due to the predominantly length-wise orientation of most of the cellulose fibrils. As it is being refined, the fiber takes up increasing amounts of water, becoming more swollen. Second, depending on the intensity of refining, some of the fibers may be broken or "cut" (Baker 1995). The word "intensity" refers to the quotient of mechanical energy expended during a given time period, divided by the number of individual impacts between fibers and the edges of the bars within the refiner. A relatively high intensity of refining is more likely to result in forces that exceed the tensile strength of a fiber. By refining fibers at a lower intensity it is usually possible to develop bonding strength with less reduction in fiber length (Corson 2002; McDonald et al. 2004). 


\section{Unit Operations of Papermaking}

During a typical papermaking operation, a suspension of fibers passes through a series of unit operations. Table 1 describes the main function of such operations in a typical, but relatively simple paper machine system. The table also lists an estimated level of hydrodynamic shear stress, and a statement about how the operation is likely to affect the uniformity of the resulting paper.

\begin{tabular}{|c|c|c|c|}
\hline Unit Operation & Function & $\begin{array}{l}\text { Hydrodynamic } \\
\text { Shear }(\mathrm{Pa})\end{array}$ & $\begin{array}{l}\text { Effects on Paper } \\
\text { Uniformity }\end{array}$ \\
\hline Machine chest & $\begin{array}{l}\text { Provide and mix a supply } \\
\text { of papermaking materials }\end{array}$ & "Low" & $\begin{array}{l}\text { Chemicals added early in the } \\
\text { process have less effect on } \\
\text { paper uniformity. }\end{array}$ \\
\hline Tickle refiner & $\begin{array}{l}\text { Allow operators to } \\
\text { shorten fibers and slow } \\
\text { rate of dewatering }\end{array}$ & "Highest" & $\begin{array}{l}\text { Shorted fibers have a } \\
\text { reduced tendency to form } \\
\text { flocs. }\end{array}$ \\
\hline Fan pump & $\begin{array}{l}\text { Dilute the stock from } \\
\text { about } 4 \% \text { solids to about } \\
0.5 \% \text { solids }\end{array}$ & 20,000 * & $\begin{array}{l}\text { The diluted stock has a } \\
\text { much reduced tendency to } \\
\text { form flocs. }\end{array}$ \\
\hline $\begin{array}{l}\text { Hydrocyclone } \\
\text { cleaners }\end{array}$ & $\begin{array}{l}\text { Remove heavy grit, sand, } \\
\text { etc. }\end{array}$ & "Very high" & $\begin{array}{l}\text { Intense shear can break } \\
\text { down high molecular mass } \\
\text { polyelectrolytes. }\end{array}$ \\
\hline Pressure screens & $\begin{array}{l}\text { Remove large objects, } \\
\text { e.g. incompletely pulped } \\
\text { fiber bundles }\end{array}$ & $10,000 *$ & $\begin{array}{l}\text { Fibers have to pass } \\
\text { individually through the } \\
\text { screen slots. }\end{array}$ \\
\hline $\begin{array}{l}\text { Headbox tube } \\
\text { expansions }\end{array}$ & $\begin{array}{l}\text { Deflocculate the } \\
\text { suspension }\end{array}$ & "High" & $\begin{array}{l}\text { Extensional flow is effective } \\
\text { in disrupting fiber flocs. }\end{array}$ \\
\hline Headbox slice & $\begin{array}{l}\text { Accelerate the jet of stock } \\
\text { onto the forming fabric }\end{array}$ & $100 *$ & $\begin{array}{l}\text { The shear flow results in } \\
\text { some fiber alignment in the } \\
\text { machine direction. }\end{array}$ \\
\hline Free jet of stock & $\begin{array}{l}\text { Fibers in web start to } \\
\text { become immobilized }\end{array}$ & "Very low" & $\begin{array}{l}\text { Fiber flocs partly re-form } \\
\text { within the free jet. }\end{array}$ \\
\hline $\begin{array}{l}\text { Jet impingement } \\
\text { onto forming } \\
\text { fabric(s) }\end{array}$ & $\begin{array}{l}\text { Adjustments in relative } \\
\text { speed of jet and fabric } \\
\text { can affect web structure }\end{array}$ & "High" & $\begin{array}{l}\text { "Rushing" or "dragging" can } \\
\text { break up fiber flocs. ** }\end{array}$ \\
\hline $\begin{array}{l}\text { Hydrofoils of } \\
\text { forming blades }\end{array}$ & $\begin{array}{l}\text { Vacuum and pulsations } \\
\text { cause more rapid release } \\
\text { of water from paper web }\end{array}$ & $500 *$ & $\begin{array}{l}\text { Foils under forming fabric } \\
\text { can moderately improve } \\
\text { formation uniformity. }{ }^{* *}\end{array}$ \\
\hline \multicolumn{4}{|c|}{$\begin{array}{l}\text { * Tam Doo et al. (1984) } \\
\text { ** Svensson and Österberg 1965; Parker 1972; Manson 1996; Swerin and Mähler 1996; Swerin } \\
\text { and Ödberg } 1996 \\
\text { *** Walser et al. 1970; Kiviranta and Paulapuro (1992); Eames 1993; Schiher and Getman 1994; } \\
\text { Manson 1996; Condon 1996; Södergren and Neun (2000); Norman 2000; Keller and Lucas } \\
(2002)\end{array}$} \\
\hline
\end{tabular}

The item called "pressure screens" in Table 1 deserves comment. As stated in the table, only individual fibers can pass through the openings of a typical pressure screen used in a paper machine system. However, such fibers can have various fine particles attached to them. For example, a fiber with attached calcium carbonate particles would not be disadvantaged in any way from passing through the screen. On the other hand, the 
hydrodynamic shear might cause some of the fine particles to be dislodged. Papermakers can fine-tune the results of their operation by choosing to add a high-mass flocculant either before or after a pressure screen (Hubbe and Wang 2002). Issues of this nature will be considered in detail later in this article (see Selective Detachment).

In addition to the functions listed in Table 1, the unit operations of papermaking also provide the operators with numerous potential points of addition for chemical additives. By selecting different points of addition, the operator can, in effect, choose the conditions of mixing, the length of time that each chemical will be exposed to the fiber suspension before formation of paper, and also the maximum shear stress to which the additives are likely to be exposed. An optimum sequencing of the chemical additives, relative to existing unit operations, can have large influences on process efficiency and product quality (Wågberg and Lindström 1987; Swerin et al. 1993; Åsselman and Garnier 2001; Hubbe and Wang 2002; Hubbe 2005b).

\section{What All Has to Come Together}

Let's suppose that you are on a team that has been asked to improve the recipe and addition points for chemical additives needed to make certain grade of paper. The team's assignment is to improve the paper's uniformity, while still maintaining good retention and keeping other properties the same. In such a situation it can be useful to imagine an ideal, exceptionally high-quality wet-web of paper coming off of a forming fabric. Next, one works backwards and thinks about the preceding steps that must have occurred in order to reach that point. The following list summarizes some attributes of the wet web of a typical grade of paper or paperboard that might have earned it the description of "exceptionally high quality:"

1. A near-random (or better) spatial distribution of fibers in the X-Y plane

2. Suitably low levels of either fiber clumps or void areas associated with fiber flocculation (especially in size range of 1-10 mm)

3. A high percentage of attachment to long fibers by any fine, particulate material present in the mixture, ensuring efficient retention in the web of paper

4. A fine, porous structure of the wet web that allows relatively rapid release of water by gravity and hydrofoil action, while avoiding large pinholes that would adversely affect the efficiency of vacuum dewatering

In order for any papermaking strategy to achieve all four of the listed objectives simultaneously, it would need to take into account factors acting at both the colloidal and the macroscopic ranges of size. The complexity of the situation can be appreciated if one examines a statement such as "let's just apply sufficient hydrodynamic shear just before the slurry leaves the headbox so that all of the solids are dispersed from each other and the paper is completely random." As described in the following section, one of the problems with the previous statement is that flocs in a fiber slurry can form again within milliseconds (Farnood et al. 1993; Condon 1996), though details of the shear-history of the fibers can affect the results. Another issue to be concerned with is that complete dispersion of all of the fine particulate matter from fiber surfaces and from agglomerates of particles can be expected to reduce the efficiency of retention during the forming 
process (Van de Ven 1984). Further issues related to the statement in quotes will be considered in subsequent sections.

Developers of papermaking chemicals might consider a different possibility while reading the remaining parts of this article. Suppose that it were possible to design a chemical additive that selectively causes agglomeration or deposition of very fine materials, such as sizing agent particles and filler particles, and suppose that the chemical has very little tendency to aggravate the flocculation of fibers. Such a strategy would be expected to achieve at least the first three objectives of the preceding list. All that remains to be done is to invent that chemical.

Yet another scenario to keep in mind, especially when reading the later parts of this article, is whether it is possible to design chemical treatments that allow the solid components of paper to come back together efficiently and remain attached just as the paper sheet is in the process of dewatering. As will be described, such a scenario may be important with respect to item 4 of the preceding list. However, before considering such possibilities, the next section will consider factors that affect fiber flocculation in the absence of chemical treatments.

\section{UNAVOIDABLE, BUT MANAGEABLE: FLOCCULATION AS A MECHANICAL PHENOMENON}

\section{Crowding}

Imagine a single, straight fiber of length $l$ suspended in a fluid undergoing laminar shear flow. The word shear implies a steady gradient of velocity as one moves in a direction perpendicular to the streamlines of flow. As has been shown (Adler et al. 1981; Takamura et al. 1981), such a fiber will tend to rotate about its center as it responds to the flow around it. Next, imagine a suspension composed of such fibers. As one might anticipate, the rotating motions of adjacent fibers easily can result in mutual collisions.

As a first attempt at predicting how the attributes of fiber suspensions might affect the likelihood of inter-fiber collisions, Mason (1954) defined a critical fiber concentration (CFC). The concept is illustrated in Fig. 1. As shown, at the CFC each fiber has just enough surrounding space so that it can rotate about its center in any direction without experiencing any collisions. The regular, non-overlapping spacing depicted in Fig. 1 is not intended to be realistic. Nevertheless, the concept has been shown to be useful in predicting volume-concentration $C_{\mathrm{V}}$ for which inter-fiber collisions are either relatively rare $\left(C_{\mathrm{V}}<C F C\right)$ or increasingly frequent $\left(C_{\mathrm{V}}>C F C\right)$.

A further logical step, still based on the situation described in Fig. 1, involves the concept of a crowding factor, $N_{\mathrm{c}}$ (Kerekes and Schell 1992; Kerekes 1995). If two fiber suspensions have the same value of $N_{\mathrm{c}}$, then they are expected to have about the same tendency to form flocs resulting from flow-induced collisions. The crowding factor has been defined as follows,

$N_{\mathrm{c}}=2 / 3 C_{\mathrm{v}}(L / d)^{2}$

where $C_{\mathrm{v}}$ is the volume fraction of fibers, $L$ is fiber length, and $d$ is fiber diameter. 


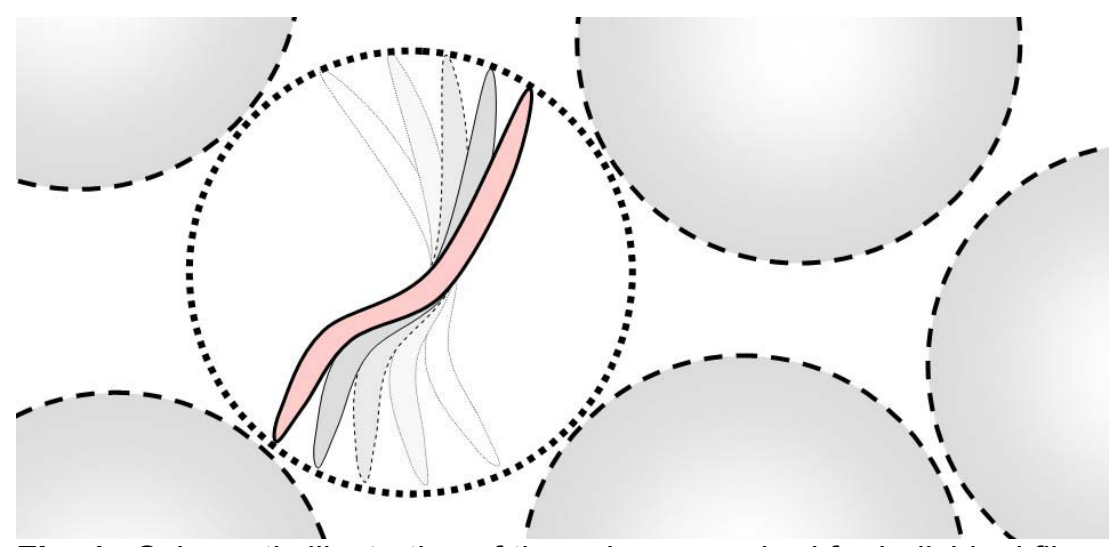

Fig. 1. Schematic illustration of the volume required for individual fibers to rotate freely without colliding with neighboring fibers

Based on Eq. (1) it would be expected that flocculation ought to increase as the first power of the solids content and as the second power of the ratio of length to thickness of the fibers. It has been found that with increasing values of $N_{\mathrm{c}}$ within the range 1 to 60 , the frequency of collisions increases from occasional to frequent, and for $N_{\mathrm{c}}>60$, the contact amount fibers in a stirred suspension becomes almost continuous and persistent flocs become apparent. To place these numbers into context, the value of $N_{\mathrm{c}}$ in the approach flow to most paper machine forming sections is in the upper quadrant of the "occasional to frequent" collision range (Kerekes and Schell 1992). In other words, papermakers face the challenge of preparing a relatively uniform product despite the fact that the component fibers are frequently colliding with their neighbors as a result of flow. Though it is theoretically possible for papermakers to form paper from much more highly dilute suspensions, the amount of pumping and the size of equipment required for such practices is usually considered to be cost-prohibitive. Recent efforts have been aimed at applying Eq. (1) in the case of mixtures of different sizes of fibers with improved precision (Huber et al. 2003).

\section{Fiber Collisions in Real Systems}

Given the simplifying assumption that were made in the derivation of Eq. (1), one should not be too surprised to find ways in which real fiber slurries show deviations, e.g. cases where suspensions having equal values of $N_{\mathrm{c}}$ show different flocculation tendencies. Table 2 lists some characteristics of fiber suspensions that either increase or decrease the tendency of a fiber suspension to flocculate, relative to what would be predicted based on the $N_{\mathrm{c}}$ value of a typical fiber suspension.

\section{Locking of Fibers into Persistent Flocs}

Only on a rare occasion would a paper machine superintendent permit a visitor to lean over the moving fabric upon which paper is being formed. Not only is the situation dangerous, but anything falling from the visitor's pocket might tear a hole in the fabric or damage a press roll, causing thousands of dollars in repair costs, plus the value of lost production time. We are all very fortunate that such permission was granted to Farnood et al. (1993). These researchers used dual-laser light backscattering to observe the state 


\begin{tabular}{|l|l|}
\hline $\begin{array}{l}\text { Table 2. Factors that tend to Increase of Decrease Flocculation in Comparison } \\
\text { to the Predictions of the Crowding Factor Equation }\end{array}$ \\
\hline & Literature References \\
\hline Increased Flocculation & Beghello and Eklund 1997 \\
\hline Persistent curl in the fibers & Beghello and Eklund 1997 \\
\hline Unusually high length-to-thickness ratio & Egelhof 1972; Kerekes and Schell 1992 \\
\hline Long fibers present in a mixture & Kropholler and Sampson 2001 \\
\hline Wider length distribution with same mean & Stoere et al. 2001 \\
\hline High level of surface fibrillation & Kerekes and Schell 1995; Dodson 1996 \\
\hline Increased fiber stiffness & Egelhof 1972 \\
\hline Increased temperature (lower viscosity) & \\
\hline & \\
\hline Decreased Flocculation & Beghello and Eklund 1997; Kerekes 1995; \\
\hline Increased fiber flexibility & Ross and Klingenberg 1998; Wikström and \\
& Rasmuson 1998 \\
\hline Unusually low length to thickness ratio & Kerekes and Schell 1992; Kerekes 1995 \\
\hline Presence of debris, acting as a lubricant & Peterson 1994; but see also Beghello 1998 \\
\hline Unequal sized objects & Mason 1954; Van de Ven and Mason 1981 \\
\hline Increased fluid viscosity & Kerekes 1995 \\
\hline
\end{tabular}

of flocculation within the jet of papermaking furnish at different locations between the headbox slice opening and the early parts of a forming fabric. As the suspension emerged from the slice opening, the fibers appeared to be well dispersed. But when the researchers moved the laser just $100 \mathrm{~cm}$ downstream from the slice opening (less than 0.1 seconds later in the process), the fibers already had become substantially flocculated. Condon (1996) reported similar observations in which the fibers in a jet of stock became substantially reflocculated within $75 \mathrm{~mm}$ of the slice opening, corresponding to about 12 milliseconds of elapsed time.

When explaining the observations just described, it is usual first to refer to the frequencies of inter-fiber collisions, as summarized in the previous subsection. However, the crowding factor, by itself, cannot explain how flow-induced fiber flocs can be strong enough to persist through the forming operation and end up in the finished paper. The dramatic change from a high state of dispersion to a state in which the fibers appear to be "locked" into flocs calls for a more complete explanation.

As proposed by Meyer and Wahren (1964), Chang and Robinson (1967), and Parker (1972), a fiber subjected to hydrodynamic shear becomes momentarily bent, and an instant later it can become locked together with other fibers while trying to straighten itself out. Floc structures formed in this manner appear to be held together by the stored elastic energy in the partially bent fibers, in combination with inter-fiber friction (Kerekes et al. 1985; Farnood et al. 1994; Andersson et al. 1999; Schmid and Klingenberg 2002; Björkman 2003; Gosz et al. 2003; Swerin and Ödberg 1997). The validity of the mechanism is supported by the fact that flocs do not form readily when the solution phase viscosity is increased (Beghello 1998); higher viscosity presumably prevents fibers from snapping back into shape quickly enough to interlock the system. In addition, fiber flocs tend to form most prominently just beyond a point where shear stresses are reduced (Jacquelin 1968; Björkman 2003; Kerekes et al. 1985). 
Figure 2 illustrates some of the simplest flocs that could be formed by this "bend and then lock into flocs" mechanism (Parker 1972). While the simple structures shown in Fig. 2 can help illustrate the mechanism, observations of stirred fiber suspensions make it clear that typical flow-induced fiber flocs can involve large numbers of fibers. Yeung et al. (1997) envisioned a process in which structural members of a floc rearrange themselves and gradually densify under continued hydrodynamic shear.
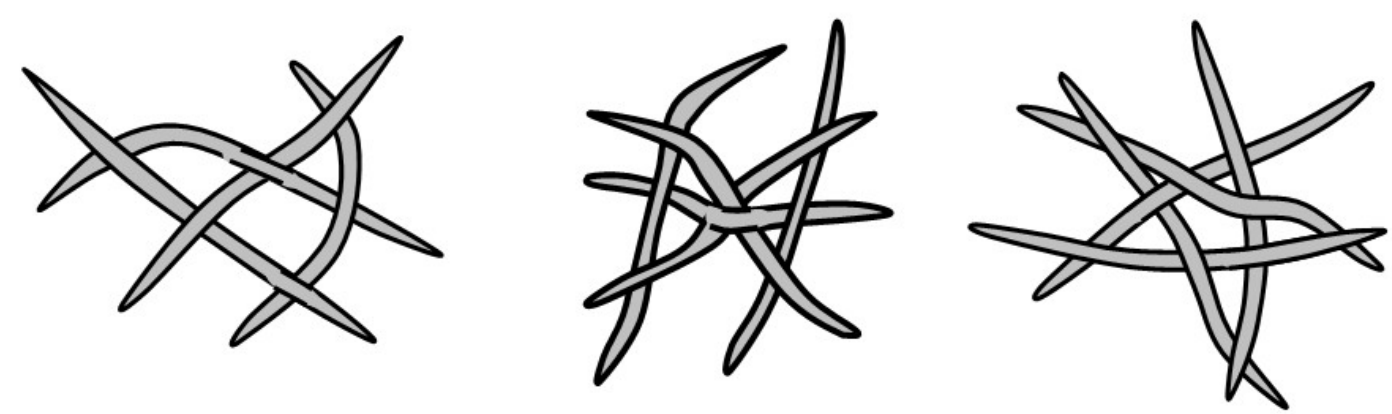

Fig. 2. Illustration of three of the simplest self-locking flocks, according the Parker (1972).

\section{Healing}

Though less obvious in comparison to the flocculation and locking mechanisms described in the previous two subsections, a phenomenon called "healing" or "smoothing" tends to make the resulting paper somewhat more uniform than it would have been otherwise (Gorres et al. 1986; Norman et al. 1995; Norman 2000). Imagine a paper test sheet being formed on a screen from a highly dilute slurry of flocculated fibers. Already there are some fibers resting on the screen surface. As other fibers and fiber flocs approach the screen, the flow veers around the already occupied areas of screen surface (Sampson 1997). Relatively few fibers "land" on the part of the screen already occupied by fiber flocs, due to the greater flow resistance in those locations. In the case of handsheets, some authors have suggested that such a healing effect can result in paper that is significantly more uniform than would have resulted from a completely random placement of fibers (Norman et al. 1995; Norman 2000). Under typical machine-made papermaking conditions, it appears that healing effects usually are obscured by the forementioned flocculation effects (Sampson et al. 1995).

\section{Flow and the Transient Breakdown of Flocs}

If one thinks in terms of the "spring-loaded" nature of fiber flocs, resulting from the flow-induced bending and subsequent straightening, then it stands to reason that continuing exposure to hydrodynamic forces of similar intensity ought to be able to overcome the bending forces that hold flocs together. Studies have identified two main ways in which shear flow tends to break down fiber flocs (Pandya and Spielman 1982; Lee and Brodkey 1987). On the one hand, fibers may be eroded from the surface of a floc (Healy and La Mer 1964; Spicer and Pratsinis 1996). On the other hand, a floc may be split in two (Kolmogorov 1949; Hinze 1955; Higashitani et al. 1989). Investigators have proposed quasi-equilibrium states in which the rates of floc formation and destruction are balanced (Kaji et al. 1991; Spicer and Pratsinis 1996). 
Because shear flow results when fluid flows parallel to a surface, e.g. in the case of flow within a pipe, it is important to consider how effectively shear flow can break up fiber flocs. Two main disadvantages can be expected if one relies just on shear flow to break up flocs. First, as already has been described, the "bend, straighten and lock" mechanism will continue to produce additional flocs, possibly resulting in a dynamic equilibrium. Another problem is that shear flow, instead of "pulling" directly on a floc, will tend to make it rotate (Adler et al. 1981: Takamura et al. 1981), a factor that tends to lessen the tensile force exerted by the flow.

Much more effective disruption of fiber flocs can occur if a fiber suspension experiences extensional flow, a condition in which there is a gradient of velocity parallel to the streamlines of flow (Kerekes 1983; Higashitani et al. 1989; Li et al. 1995; Li and Ödberg 1997; Shah 2002). Extensional flow can manifest itself, for instance, when fluid passes into an opening or at an expansion in a tube. Kerekes (1983) showed that fiber flocs passing into a tube tended to become greatly elongated, almost to the breaking point. Contractions in flow channels also have been found to be extremely effective for stretching and breaking macromolecules (Nguyen and Kausch 1992), an effect that is attributed to extensional flow. Transient extensional flow events also occur within turbulent flow (Liu and Glasgow 1997); however such events appear to be of too brief duration to be highly effective in fragmenting flocs (Wagle et al. 1988).

There are three critical points in the papermaking process at which papermakers take particular advantage of extensional flow effects in ways that tend to pull fiber flocs apart.

1. The pressure screens in a typical paper machine system give rise to extensional flow as the suspension is forced to pass through small slots or holes (Bliss 1996). Flow accelerates and then decelerates as an element of liquid enters and emerges from an opening in the screen. The effect on fiber flocs is further enhanced by the fact that the openings in the screen are designed to be just large enough to permit passage of individual fibers, due to their size and flexibility.

2. Extensional flow effects are imposed upon fiber suspensions within the tube banks on the intake side of certain hydraulic headboxes (Kiviranta and Paulapuro 1990; Bonfanti et al. 2000). The tubes are intended to deliver uniform flow, pressure, and velocity across the width of a paper machine forming section. By designing sudden expansions within such tubes, fiber flocs can be pulled apart more effectively.

3. Perhaps most importantly, the velocity of flow becomes accelerated considerably as it passes through the headbox slice, which functions something like a nozzle. The strong alignment of fibers (Ulmar and Norman 1997), as well as the elongation of flocs (Praast et al. 1998), in the direction of manufacture of machine-made papers appears to originate partly due to extensional flow during passage through the slice. The observations, cited earlier, of substantial absence of fiber flocs immediately after the slice opening can be viewed as a testament to the effectiveness of such extensional acceleration in disrupting fiber flocs. One has to be careful, however, since acceleration of flow within a nozzle also imparts hydrodynamic shear, which is maximized at the fixed surfaces, and it was noted 
earlier that such shear flow will tend to bend fibers, making it more probable that they become locked together as flocs a moment later.

"Passive" is perhaps the best adjective to describe the approach that paper machine operators take with respect to the three phenomena mentioned above. Once a paper machine has been installed, there is no easy way to make significant adjustments to the workings of a certain pressure screen, the design of the tubes entering the headbox, or the shape of the slice. Papermakers can take a more active roll when they adjust the relative angle and velocity at which the jet of furnish lands on the surface of a forming fabric. A relatively shallow angle of impact, often described as "velocity forming," is least disruptive to the nascent fiber mat structure within the jet. A relatively steep impact, often called "pressure forming," gives the papermaker an opportunity to break up fiber flocs, though there is no guarantee that the net effects of pressure forming will be favorable in terms of customer requirements.

By adjustments of the fan pump flow, as well as adjustments in the pressure within the headbox system, papermakers can fine-tune the jet velocity. Many papermakers prefer to "drag" the jet of fiber, meaning that the forming fabric velocity is a few percent higher than that of the jet (Svensson and Österberg 1965; Parker 1972; Manson 1996; Swerin and Mähler 1996; Swerin and Ödberg 1996). The velocity difference not only tends to reduce the flocs in the paper, but also, there is an increased tendency for fibers to become aligned in the direction of manufacture. Such alignment of fibers in shear flow has been documented in a variety of systems (Stover et al. 1992; Orts et al. 1995). The same effects often can be achieved by "rushing" the sheet, a condition in which the jet velocity is faster than that of the fabric. Similar principles apply in the case of so-called "twin-wire" or "gap former" paper machines (Swerin and Mähler 1996), especially when one takes into account the fact that, for reasons of stability, the jet usually first impinges onto one fabric surface, before it comes into contact with the other.

\section{Management of Vortex Flow}

Before turning to chemical aspects of fiber flocculation, there is one more physical effect that can give papermakers a degree of control over the uniformity and structure of a paper sheet. That is, one needs to be aware of a tendency for vortex cells of flow to form having their axis in the direction of manufacture (Aidun 1996, 1998). Such vortices arise spontaneously in response to such factors as the abrupt cessation of shear at the upper and lower surfaces of the jet of suspended fibers as it emerges from a headbox slice (Söderberg and Alfredsson 1997). Such vortices can interact with adjacent vortices in complex ways as a paper web gradually becomes dewatered on a Fourdrinier paper machine. It is sometimes possible to minimize machine-directional basis weight or moisture streaks by adjusting the position on the forming table at which sufficient water has been removed to essentially "freeze" the basic structure of the sheet. Alternatively, more serious streakiness may persist in the product in cases where the structure becomes immobilized at a point where certain vortices having different wavelengths happen to reinforce each other.

The fact that shear flow tends to align fibers in the direction of manufacture has important implications relative to flocculation. If there were a way to choreograph fibers 
such that they all rotated in parallel orbits, then the frequency of inter-fiber collisions would be reduced considerably. This is, of course, an idealization. Turbulent components of flow, which are expected to cause chaotic fiber motions, are unavoidable within the ranges of jet velocities and jet dimensions associated with modern papermaking. Waterhouse (1993) observed that handsheets formed under oriented flow conditions, presumably leading to fiber alignment, had much more uniform formation, compared to standard handsheets formed from suspensions of similar consistency. Recent progress has been demonstrated by a system in which a degree of twist is imposed upon the flow within the inlet tubes to a hydraulic headbox (Islek et al. 2004). Reported improvements in formation uniformity in such systems supports the idea that inter-fiber collisions and floc development were somehow decreased by controlling the orientations of fiber rotation.

\section{FLOCCULATING EFFECTS OF CHEMICAL ADDITIVES}

\section{Evidence that Polyelectrolytes Can Act like Bridges}

As mentioned in the introduction, adding polyelectrolytes having very high molecular mass to a suspension of cellulosic fibers often increases the observed degree of flocculation. Increased strength of flocs and fiber networks also has been demonstrated, resulting from such treatments (Swerin et al. 1992). Commercial acrylamide-based retention aid products can be describes as "huge," having molecular masses generally in the range of about 4 to 20 million Daltons. Acrylamide copolymers having up to $10 \%$ cationic monomer groups are especially popular, since they adsorb readily onto the negatively charged surfaces of cellulosic fibers. Given the fact that most papermakers add either aluminum compounds, polyamines, or cationic starch at some point in the process, anionic copolymers of acrylamide also function very well as retention aids in many papermaking systems.

Use of the term "bridging" to describe the action of very-high molecular mass polyelectrolytes goes back to work by La Mer and Healy (1963) and Gregory (1976). These investigators noted that the very large molecules were able to agglomerate suspended solids even in cases where the average electrostatic repulsions between predominantly negatively charged surfaces would have been sufficient to inhibit interparticle collisions. Observed agglomeration rates were consistent with a model in which each suspended particle was only partly covered by polyelectrolyte at the point of maximum agglomeration (Fleer and Lyklema 1974; Gregory 1976). In certain cases it was possible to observe rates of flocculation in excess of what could be achieved by simple ions; these effects were attributed to the extension of polymer tails out from the solid surfaces (Gregory 1973). Flocculation was found to decrease with time, following addition of the polyelectrolyte solution (Gregory and Sheiham 1974; Forsberg and Ström 1994). This effect was attributed to macromolecular fragmentation or gradual flattening of the adsorbed conformations. The fact that flocculating ability increased markedly with molecular mass was taken as further evidence that the mechanism involved the ability of single macromolecules to bridge the space between pairs of suspended objects, essentially adsorbing onto two surfaces at once. 
Figure 3, an illustration of macromolecular bridging flocculation, emphasizes certain aspects of the process. First, there tends to be more attachment of fine particles on fibrils of a cellulosic fiber, rather than onto the main part of the fiber (Haslam and Steele 1936; McNeal et al. 2005). One way to understand this trend is based on a hydrodynamic lubrication effect, whereby particles of unequal size that are on a collision course in shear flow tend to deviate from their undisturbed streamlines, due to the viscosity of the fluid between them (Mason 1954; Brenner 1968; Adler et al. 1981; Van de Ven and Mason 1981). Another way to picture what is happening is that the fibrils tend to intercept strands of the polyelectrolytes due to relative flow past the fiber surface. The entrapped macromolecules or strands of macromolecules then can act like a sort of fishnet, trapping fine particles (Lindström and Glad-Nordmark 1984). Whatever the explanation, it can be shown that the resulting attachments, in the wet state, are much stronger in comparison to what can be achieved by simple ions (Hubbe 1987ab).

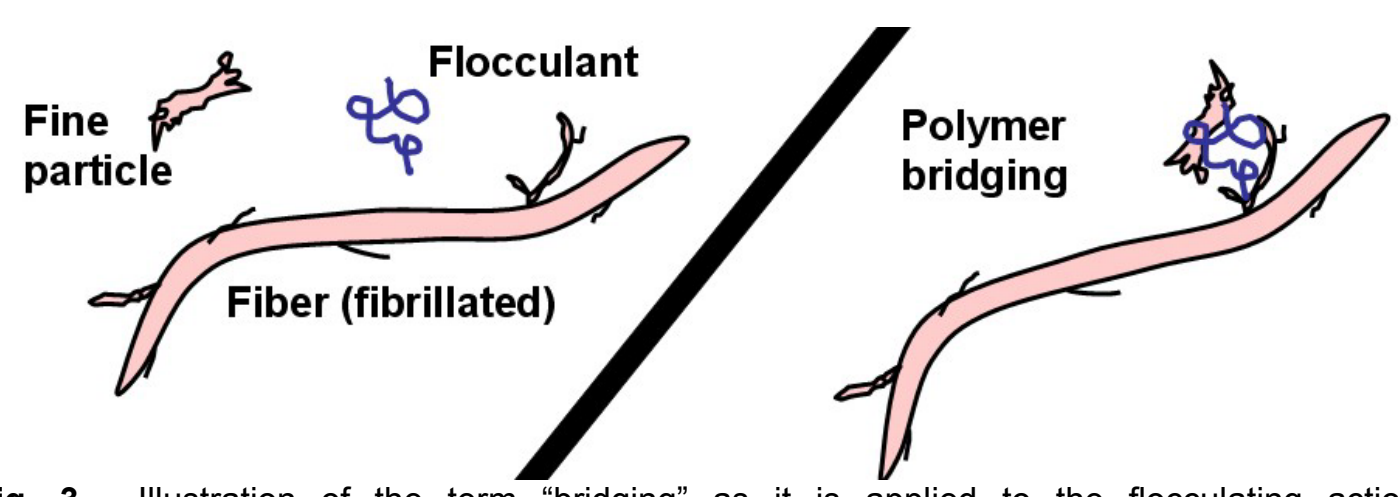

Fig. 3. Illustration of the term "bridging" as it is applied to the flocculating action of polyelectrolytes having very high mass

In addition to "strong," the word "brittle" also can be used to describe the macromolecules that form polymeric bridges. Studies have shown that agitation of fiber suspensions flocculated by very-high-mass polyelectrolytes tends to reduce the mean molecular mass substantially (Sikora and Stratton 1981; Tanaka et al. 1993; Forsberg and Ström 1994). Once bridge-type attachments are broken, any fiber flocs that form subsequently will not be of as high strength (Unbehend 1976; Hubbe 2000a). Unbehend (1976) defined the term "hard flocs" to describe the structures formed as a result of veryhigh-mass polyelectrolyte addition. The brittle nature of such polymer bridges can be rationalized based on the very large chain lengths of the polyelectrolyte molecules that can adsorb simultaneously onto two surfaces in an extended, three-dimensional manner. To place things into perspective, if a retention aid molecule were as thick and angel-hair spaghetti, its fully extended length would span a football field.

Paper that is formed from flocculated fiber suspensions tends to be weak. In a revealing set of experiments, Roberts et al. $(1986,1987)$ observed that paper's tensile strength either decreased, increased, or stayed about the same, depending on how long a fiber suspension was mixed following treatment with cationic starch, a well-known drystrength agent. To explain the results, it was noted that initial introduction of the cationic starch solution produced extensive flocculation. Continued agitation appeared to 
gradually break the chemical-induced attachments between fibers, resulting in a welldispersed suspension.

Various factors affect both the efficiency of cationic acrylamide copolymer retention aids and their tendency to flocculate fiber suspensions. The effectiveness of such polyelectrolytes can be significantly reduced if substantial amounts of negatively charged colloidal materials are present in the process water (Krogerus 1993; Dunham et al. 2000). The cationic macromolecules appear to form complexes with the anionic colloidal material, rather than interacting efficiently with fiber and particle surfaces. In such cases, retention aid efficiency often can be substantially improved by pretreating the system with a high-charge cationic additive (Wågberg and Ödberg 1991; Swerin et al. 1996b; Dunham et al. 2000). In addition to neutralizing the colloidal material in the mixture, the high-charge cationic additives also can cause the subsequently added cationic retention aid molecules maintain more extended conformations in the adsorbed state (Swerin et al. 1996b). When papermakers employ anionic acrylamide copolymers as retention aids, retention performance similarly can be enhanced by pretreating the system with something that is strongly cationic (Allen and Yaraskavitch 1989; Petzold et al. 1996; Petzold 1999). The cationic additives, after becoming adsorbed, appear to provide sites on the solid surfaces, to which the subsequently added anionic retention aid molecules can attach. Retention aid efficiency also tends to decrease as the salt concentration becomes relatively high (Buontempo et al. 1996), an effect that most likely can be attributed to decreased molecular extension in the adsorbed state (Fleer et al. 1993; Wågberg 2000).

\section{Effects of Charged Patches Formed by Polyelectrolytes}

Given the evidence that bridging-type flocculants can markedly decrease paper's uniformity, papermakers have had a strong incentive to consider additives that function in a somewhat different way, while still contributing to the retention of fine particles. Studies have shown that the highly branched, highly cationic macromolecule polyethyleneimine (PEI) tends to adsorb onto surfaces in a patch-like manner (Pfau et al. 1999; Horn 2001). As suggested by Fig. 4, such patches on cellulosic fibers, latex binders, and other negatively charged matter would be expected to act as isolated areas of positive charge. In theory, the presence of oppositely charged patches on surfaces within a suspension can be expected to promote agglomeration of the suspension (La Mer and Healy 1963; Kasper 1971; Gregory and Sheiham 1974; Sandell and Luner 1974). To the degree that the term "patch" is valid, one would expect such agglomeration to be reversible in the presence of varying degrees of hydrodynamic shear. In other words,
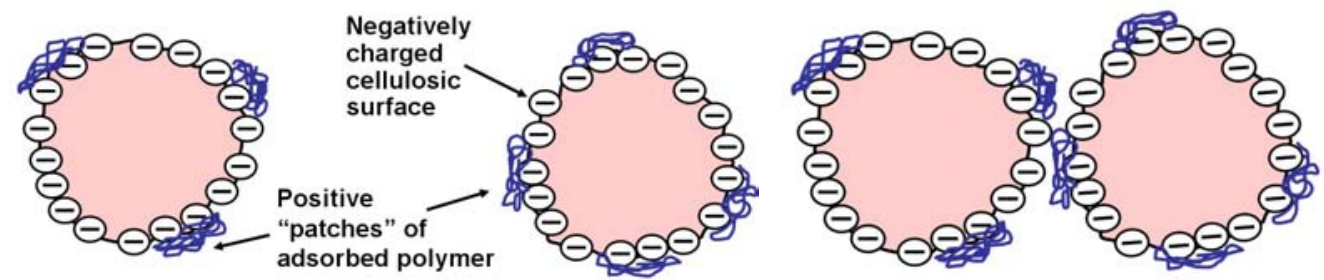

Areas of contrasting charge contributing to attraction

Fig. 4. Illustration of the "charged patch" mechanism of polyelectrolyte adsorption and subsequent coagulation of suspended solids by electrostatic attraction 
vigorous agitation might be expected to redisperse solids that had become agglomerated due to a charged-patch mechanism, but the suspension would be expected to agglomerate again when hydrodynamic forces are reduced.

In support of the "charged patch" mechanism of agglomeration, Goossens and Luner (1976) flocculated microcrystalline cellulose (MCC) by addition of poly-ionene, having a molecular mass of 60,000 Daltons. Based upon the fact that the maximum in flocculation did not correspond to zero zeta potential, these authors, as well as others (Beck et al. 1977; Petzold 1999), have concluded that charged patches must be involved. The tendency for the MCC to agglomerate decreased with continued agitation, consistent with a process of gradual spreading out of the polymer over the available surfaces. In an indirect demonstration of the same concept, Das and Lomas (1973) treated some of the fine matter from a papermaking system with moderate-mass PEI, essentially making those particles into solid patches of charge, and having the opposite charge compared to other surfaces in the suspension. The resulting flocs were much stronger than would have been expected based on neutralization of charges.

Jokinen and Palonen (1986) found that high-charge, moderate-mass cationic polyelectrolytes were able to retain fine materials with relatively little adverse effect on paper's uniformity. However, such additives were not able to achieve the high levels of retention efficiency that were obtained with very-high-mass retention aids. More recently, Tripattharanan et al. (2004b) observed efficient retention of fiber fines and precipitated calcium carbonate filler particles following treatment of a fiber suspension with a copolymer of ethyleneimine (modified PEI) having a molecular mass of approximately 2 million Daltons. Such molecular masses are considerably lower than those that have been proposed for bridging interactions between surfaces.

\section{Charge Neutralization and Retention of Colloidal Matter}

There is abundant evidence to support a "charge neutralization" mechanism of agglomeration, i.e., coagulation (Hogg et al. 1966; Alince and Robertson 1974; Walkush and Williams 1974; Stratton and Swanson 1981). However, the ways in which coagulation affects papermaking operations can be subtle (Bjellfors et al. 1965). The idea is that elimination of electrostatic forces of repulsion allows the ever-present and attractive London dispersion forces to become dominant (Hunter 1987). Studies suggest that charge neutralization, by itself, as well as suppressing of charge effects by salt addition, usually has little effect on the uniformity of machine-made paper (Mason 1950; Beghello and Eklund 1999). Pelton (1993) suggested that the apparent ineffectiveness of London dispersion forces in flocculating cellulosic suspensions may be due to a high level of fibrillation of the surfaces, on a nanometer scale. The water-loving polysaccharide chains at the cellulosic surfaces would be expected to offer a very low Hamaker coefficient, and also tend to sterically stabilize the systems. Nevertheless, charge neutralization may play a critical role in the retention of colloids, including the very small filler particles, droplets of hydrophobic sizing agents, macromolecules, and the like.

One can envision the retention of colloidal matter during papermaking as a twostep process. In the first step, the very small particles become agglomerated together into larger entities or become deposited onto cellulosic surfaces. Marton (1974) showed that 
the effective surface area per unit mass of cellulosic fines within typical papermaking furnish can be about 3 to 5 times larger than that of the longer fibers. Because cellulosic fines often make up between 5 and $25 \%$ of the mass of paper, depending on the pulping and refining processes, one can expect a charge neutralization strategy to result in large proportion of colloidal matter becoming deposited onto the surfaces of cellulosic fines. Thus, the second step of the process of retaining colloidal matter involves retaining the fiber fines. Some fiber fines can be retained by mechanical filtration during paper formation; however, papermakers increasingly are relying upon the use of retention aid polymers, as described in the previous two subsections.

To back up the statement that charge neutralization has relatively little effect on fiber flocculation and fines retention, Tripattharanan et al. (2004b) conducted experiments with a refined bleached hardwood kraft suspension that contained $45 \%$ fiber fraction, $25 \%$ fiber fines, and $30 \%$ precipitated calcium carbonate (PCC) by mass. The electrical conductivity was adjusted to $1000 \mu \mathrm{S} / \mathrm{cm}$ using sodium sulfate. Fine-particle retention efficiency was evaluated under a variety of hydrodynamic conditions, simulating different aspects of the papermaking process. A neutral charge condition was obtained, as confirmed by microelectrophoresis, by addition of $0.1 \%$ moderate-mass poly-DADMAC, dry basis. No significant differences were observed in the turbidity of filtrate when comparing results in the presence or absence of poly-DADMAC addition.

In another set of tests, a suspension was prepared with $0.5 \%$ bleached chemithermomechanical pulp (BCTMP) pulp solids and $0.05 \%$ ground calcium carbonate (Hubbe 2000). The suspension was treated at different levels of poly-DADMAC, except that the molecular mass was higher than in the previous instance. Relatively weak fiber flocs were observed, using an optical method; however the strength of the flocs was too low to detect by means of a viscometric method. There was a maximum in the degree of flocculation if the poly-DADMAC dosage was just enough to achieve a zeta potential of zero. The relative weakness of the flocs, as well as the fact that they were maximized at the neutral point, suggests either a charged patch mechanism or a charge neutralization mechanism.

\section{SELECTIVE DEFLOCCULATION}

Papermakers appear to benefit from a kind of natural selection. As stated earlier (see "A Working Hypothesis"), it has been proposed that chemically induced linkages between fibers tend to be broken at lower levels of hydrodynamic force, compared to similar linkages between fibers and small particles, or between small particles attached to other relatively small objects. In view of the concepts outlined in the previous section, the hypothesis given earlier now can be stated in chemical, as well as mechanical terms. Thus, it can be proposed that when papermakers use very-high-mass retention aids under optimum conditions, the macromolecular bridges are strong enough to hold fine particles onto other various surfaces, but bridges between pairs of fibers become irreversibly broken. Before considering how different types of chemical effects and surface forces might or might not be compatible with this concept, the following subsection will 
consider some mechanical factors that appear to favor this kind of mechanism in the case of typical papermaking fiber suspensions.

\section{Implications of Sizes, Shapes, and Flows}

Several authors have explained the general principle that fibers in an agitated suspension are more susceptible to becoming separated by hydrodynamic forces, in comparison to smaller objects that are attached to fibers or to each other (McKenzie 1968; King and Williams 1975; Stratton 1983; Hubbe 1984, 1986; Hubbe and Wang 2002). To rationalize this effect in quantitative terms it is necessary to consider both the sizes and the shapes of different solid entities present in a typical papermaking furnish. Realizing that mechanical pulp mixtures can comprise an extremely diverse range of sizes, the following analysis will be based on a typical hardwood kraft pulp furnish. Let us further assume that this furnish also contains calcium carbonate filler particles having a mean diameter of $2 \mu \mathrm{m}$.

Before considering the extent to which the elongated shapes of papermaking fibers affects their susceptibility to be separated by hydrodynamic forces, it is already possible to make some initial estimates based on the contrasting sizes of fibers vs. fine material. Consider the situation diagrammed in Fig. 5. The figure depicts a spherical particle adhering to a rough, planar surface that is exposed to shear flow. Even if the prevailing flow environment can be described as turbulent, it makes sense to envision flow adjacent to a surface as being part of a viscous sublayer, in which the momentary fluid motion can be described in terms of a laminar shear field (Cleaver and Yates 1973; Hubbe 1984).

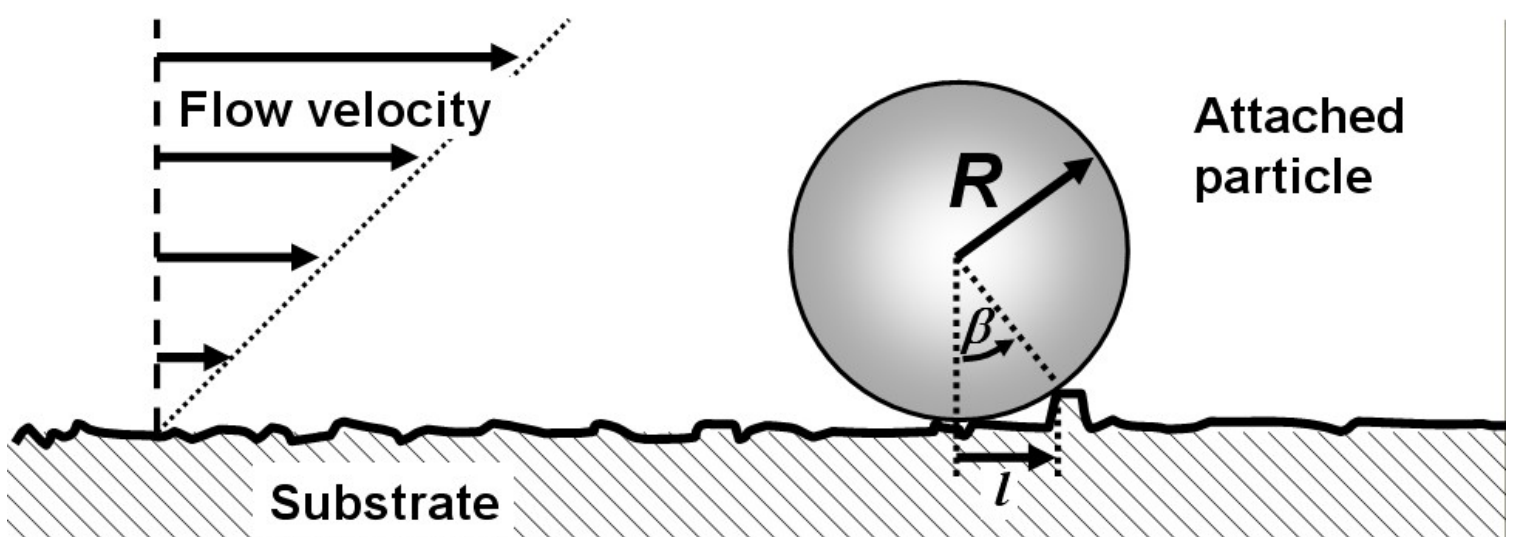

Fig. 5. Geometric model of spherical particle exposed to shear flow, to account for minimum hydrodynamic shear stress needed to cause detachment by a rolling mechanism

According to one theory, the ability of a particle to resist becoming rolled from its point of attachment depends on (a) the maximum attractive force between the particle and substrate during the process of detachment, (b) the particle size, and (c) the size of the area of contact, which is assumed to be governed by the scale of roughness on each of the solid surfaces (Hubbe 1984). Assuming that the origin of the interactive forces holding particles onto the substrate are independent of particle size, it can be shown that the attractive force ought to be proportional to the diameter of the object that is being 
modeled as a sphere (Hogg et al. 1966). The hydrodynamic force, acting to push the particle parallel to the substrate is given by the following equation (Goldman et al. 1967; O’Neill 1968),

$$
F=32.06 R^{2} \tau_{\mathrm{o}}
$$

where $R$ is the particle radius and $\tau_{\mathrm{o}}$ is the hydrodynamic shear stress at the substrate surface. Because we are interested in determining the minimum shear stress at which an attached particle begins to roll, it is also possible to estimate the torque that will result from a given level of hydrodynamic shear stress. The hydrodynamic torque can be expressed as follows:

$$
T=43.92 R^{3} \tau_{\mathrm{o}}
$$

To complete the analysis, it is necessary to make a reasonable estimate of a length scale of the contact region, as indicated by the parameter $l$ in Fig. 5 (Hubbe 1984). It follows from the figure that $l$ is given by

$$
l=R \sin \beta=R\left[(2 H / R)+\left(H^{2} / R\right)\right]^{1 / 2},
$$

where $\beta$ is the angle shown in the figure and $H$ is the height of a typical bump on the substrate that defines the length of the "level arm" $l$, tending to resist a rolling motion of the particle. At the limit of low roughness, the second term within the brackets can be neglected, and the expression can be combined with (3) to give a critical shear stress corresponding to detachment by rolling,

$$
\tau_{\mathrm{o}}^{*}=F_{\text {adhesive }} l /\left(43.9 R^{3}\right) \propto R R^{1 / 2} / R^{3} \propto R^{-3 / 2}
$$

Experimental verification of Eq. (5) was obtained in the case of different uniformly sized populations of spherical titanium dioxide particles being detached from cellulosic film and glass substrates (Hubbe 1985). The results support the statement that higher shear stress is required to cause rolling detachment of smaller particles from a surface.

The next step is to consider the shapes of entities that are to be detached by flow. Figure 6 compares two objects. The first is a roughly spherical object having the same radius as that of the cross-section of a typical hardwood fiber. The second object represents a hardwood fiber having one end projecting outwards into the solution phase. Let us suppose, for example, that the fiber is about 50 times as it is wide and that the tip of the fiber projects ten fiber widths away from the "crossing point" at which it is in contact with another fiber. The hydrodynamic torque exerted on the fiber, in comparison to that exerted on the spherical object, can be estimated from

$$
T_{\text {fiber }}=T_{\text {sphere }} \int_{0}^{10} L \mathrm{~d} L=1 / 210^{2} T_{\text {sphere }}=50 T_{\text {sphere }}
$$


To estimate the ratio of shear stress required to detach the fiber, shown in Fig. 5, in comparison to a typical filler particle having a radius of $1 \mu \mathrm{m}$, one combines the results expressed in equations (5) and (6).

$$
\text { Ratio }=(20 \mu \mathrm{m} / 2 \mu \mathrm{m})^{1.5} \times 50 \approx 1600
$$

This result, though very approximate, suggests that a much more intense flow would be required to detach a filler particle from a fiber surface, in comparison to the flow event required to detach two fibers from one another, assuming that the forces holding the objects together have similar origin.

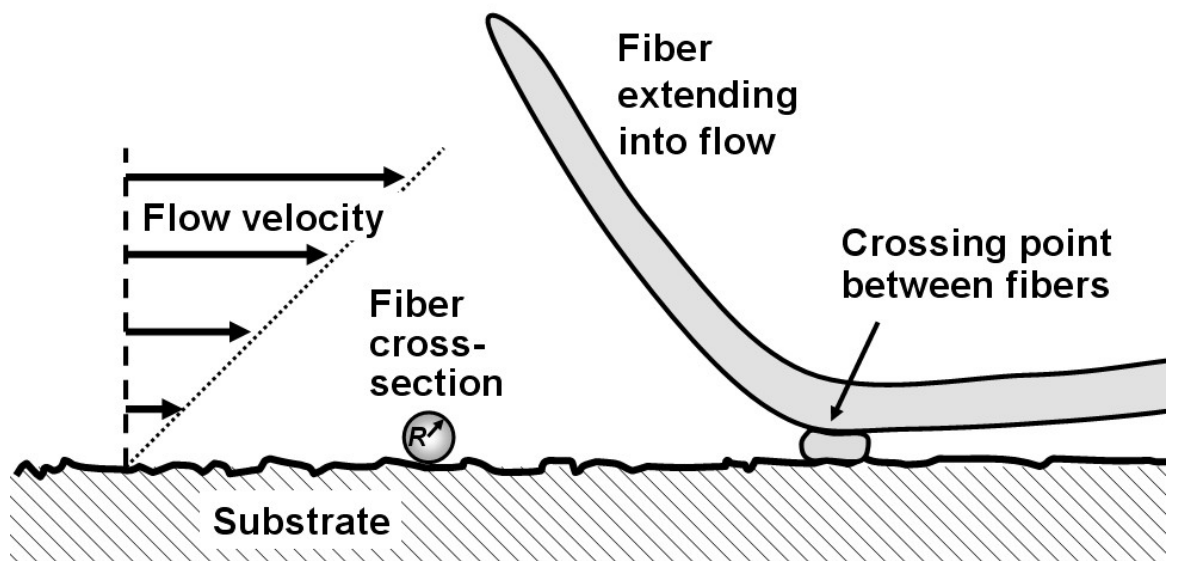

Fig. 6. Geometric diagram to compare the torque exerted by hydrodynamic shear on a particle of radius $R$ versus a fiber having a similar cross-section

\section{Evidence of Selective Deflocculation}

Relatively little research has been published to demonstrate that fine particles are indeed less likely to be detached by hydrodynamic shear, compared to the separation of pairs of fibers. An exception is one study in which a slurry of bleached chemithermomechanical pulp and ground calcium carbonate filler was treated with a very-high-mass cationic acrylamide copolymer (Hubbe 2000). It was shown that fiber flocs were substantially broken down by passing the suspension through a peristaltic pump. After exposing the fibers to a kitchen blender, the chemically-induced flocs were irreversibly broken, and the degree of fiber flocculation was not significantly different than that of an untreated suspension. However, even the high level of shear stress in the blender apparently was not sufficient to dislodge the filler particles from the fiber surfaces under the conditions of treatment. Measurements of filtrate sampled with a 100mesh screen before or after shearing in the blender, showed essentially the same strong reduction in turbidity with increasing dosage of the cationic flocculant added to the system. 


\section{FLOC REVERSIBILITY}

Near the beginning of this article it was proposed to envision an ideal web of paper. It might seem, following the discussion in the previous section, that many of the preconditions required for producing an ideal web might be achieved by judicious use of a high-mass flocculating polymer, followed by a well-chosen level of hydrodynamic shear. However, such a strategy still does not fully address the fourth precondition on the earlier list, i.e. "a fine, porous structure of the wet web that allows relatively rapid release of water by gravity and hydrofoil action, while avoiding large pinholes that can adversely affect the efficiency of vacuum dewatering." Lindström (1989) suggested that the key to achieving this further goal involves reversibility of the chemical-induced attachments among solid surfaces in the papermaking suspension. In other words, one makes use of colloidal attractions between the solids to increase the effect of friction between the wetted surfaces (Andersson et al. 2000; Zauscher and Kingenberg 2000). Then, during the formation and initial dewatering of the wet web of paper, the surfaces will tend to remain joined at the points of initial contact, rather than sliding around to form a dense, relatively impermeable mat.

\section{Experimental Verification of Floc Reversibility}

Hedborg and Lindström (1996) carried out pioneering work showing that the reversibility of chemically-induced flocculation can depend on the type of chemical treatment. Tests were carried out according to the "Dynamic Drainage/Retention Jar" method of Britt and coworkers (Britt 1973; Britt and Unbehend 1976), with some key modifications. In a departure from the original procedure, Hedborg and Lindström compared the solids level of the filtrate obtained when the fiber mixture was first agitated at a higher speed, versus the solids level obtained after the agitation speed had been decreased. A reversibility index was defined as

$$
I_{\mathrm{rev}}=(B-A) /(C-A)
$$

where $A$ is the fine particle retention efficiency at the higher agitation level, $B$ is the retention efficiency after a combined exposure to high shear, followed by lower shear, and $C$ is the retention efficiency in the case of steady agitation at a lower level. In each case the agitation scheme was applied after the suspension had been treated with one of more chemical additive.

Based on analyses of this type it was concluded that certain microparticle retention aid treatment programs yielded more reversible flocculation, in comparison to treatment just with very-high-mass polyelectrolyte flocculants. In other words, it was concluded that the solid surfaces were able to come back together and "stick," after being separated, in the case of treatments that included microparticles or nanoparticles, such as colloidal silica. Other researchers similarly have documented a greater ability of microparticle-type additive systems to reflocculate fiber suspensions after dispersion in shear (Swerin et al. 1993; Swerin et al. 1997; Hubbe 2001). Mechanisms related to the use of such microparticles have been described in other publications (Langley and Litchfield 1986; Anderson and Lindgren 1996; Wågberg et al. 1996; Åsselman and Garnier 2000, 2001; Hubbe 2005b). Briefly stated, it appears that sequential treatment by 
polymeric flocculants, high levels of hydrodynamic shear, and then addition of highly negatively charged colloidal particles can result in systems that favor gentle reattachment of the solid surfaces after shear, without causing excessive re-flocculation of the fibers.

In the case of treatment with cationic acrylamide copolymers, work by Ericksson and Alm (1993) showed that the degree of reversibility of flocculation can depend on the polyelectrolyte's charge density (Ericksson and Alm 1993). Bridge-type behavior, including irreversible breakdown of the flocs by shear, was found for copolymers having $10 \%$ or less of cationic monomeric groups. Systems treated with higher-charge flocculants came together again after being mechanically dispersed. Results can be interpreted in terms of a more extended adsorbed conformation of the lower-charged polyelectrolytes (Fleer et al. 1993; Wågberg 2000).

Though less attention has been paid recently to such issues, it is also well known that the "charged patch" and "charge neutralization" mechanisms of chemically-induced agglomeration also display characteristics of reversibility (Blanco et al. 2002). As noted by Horn and Linhart (1991), the ability of relatively low-mass, high-charge cationic polymers to agglomerate suspensions of negatively charged particles usually is maximized at a zeta potential near to zero. By contrast, increasing levels of very-highmass flocculants usually achieve very high levels of agglomeration long before the neutral point of surface charge has been reached.

\section{Inter-fiber Friction and Forces of Attraction}

The relationship between friction and colloidal forces was studied in detail by Zauscher and Klingenberg $(2000,2001)$. The goal of the study was to account for the ability of carboxymethylcellulose (CMC) to prevent excessive entanglement during extrusion of mixtures containing long fibers at relatively high solids levels. Results showed that adsorption of CMC not only reduced friction between cellulosic surfaces to a low level, but it also resulted in long-range forces of repulsion. In effect, the big, waterloving molecules prevented close approach of the surfaces. These results help to explain the function of "formation aids" of the type often used during the production of paper and wet-laid nonwoven fabrics (Erspamer 1940; Swanson 1950; Wasser 1978; Lee and Lindström 1989; Keith 1994; Hutton 1995; Giri et al. 2000). Such additives can make it possible to achieve well-formed sheets from fibers having much higher length-tothickness ratios compared to wood fibers. However, the high cost of formation aids, as well as their adverse effect on dewatering rates has been enough to discourage papermakers from employing similar strategies for conventional paper production.

Another way to quantify effects related to inter-fiber friction is by measuring the volume occupied by a specified quantity of fibers that are allowed to freely settle in an unstirred graduated cylinder (Kline 1967; Alince and Robertson 1974; Gruber et al. 1997). Studies of this nature have shown repeatedly that maximum sediment volumes tend to be associated with levels of chemical treatment that are just sufficient to neutralize the effect of electrostatic repulsions between the solids. It has been proposed that charge neutralization can increase the dewatering rate of papermaking furnish by allowing fine particles to coagulate onto the surfaces of fibers, rather than being free to move through the web of paper to points where they tend to clog passageways of flow (Hubbe 2002). This mechanism, together with the more bulky structure of the mat, 
achieved by the frictional effects, may account for the effectiveness of highly charged cationic polymers when they are used as dewatering aids (Allen and Yaraskavitch 1991).

\section{SUMMARY: A PRESCRIPTION FOR UNIFORMITY AND EFFICIENCY}

In summary, there are a variety of strategies that papermakers can employ in order to achieve favorable combinations of product uniformity and efficient retention of fine particles. As noted earlier, an ideal wet web ought to have a highly uniform spatial distribution of fibers, an absence of basis weight variations in the size range of about 1 to 10 $\mathrm{mm}$, efficient attachment of fine particles onto cellulosic surfaces, and a fine-scale, porous structure.

Paper machine systems and chemical additive programs can vary considerably, depending on the vintage of the equipment, the nature of the fibers, and the types of paper being produced. Detailed chemical recipes and preferred addition points and dosages of each additive need to be optimized for each specific case. Nevertheless, the work cited in this review suggests a generalized strategy, as follows:

1. To the degree that paper property requirements permit, employ fiber blends that are rich in hardwood, which tends to have a lower length-to-thickness ratio than softwood. Also, the fibers are smaller, tending to produce smaller flocs at the same value of the crowding factor $N_{\mathrm{C}}$.

2. Optimize the degree of mechanical refining of pulp to achieve inter-fiber bonding, while increasing fiber flexibility. The level of refining often will be constrained by a tendency for reduced rates of dewatering, higher apparent density of the paper, and other related effects with increased refining.

3. When using very-high-mass retention aids, select the addition point and dosage such that the remaining unit operations before the forming zone (including such items as pressure screens, tube expansions, the slice, and jet impingement) impart just enough shear to substantially disperse the fibers from each other, while failing to dislodge most of the fine particulate matter that may be clinging to fiber surfaces.

4. Employ drainage-aid strategies, possibly allowing an increase of the paper machine's fan pump flow, resulting in a lower consistency at the headbox and a lower crowding factor $N_{\mathrm{C}}$. A key constraint is whether the headbox can handle the additional flow without producing undesirable wake effects in the forming zone. Also, while the maximum speeds of some paper machines can be limited by the dewatering rate, this is not true of all paper machines. As mentioned in earlier sections, drainage strategies can be based on treatments with high-charge cationic polyelectrolytes or aluminum compounds. Certain microparticle treatment programs have the potential to accelerate dewatering rates significantly.

5. Employ a variety of equipment-related strategies, as mentioned in earlier sections. For example, fine-tune the jet-to-wire speed difference, adjusting the state of rush or drag. Adjustments also can be made to the spacing or types of foils or forming blades over which the forming fabric travels. 
6. Continue to optimize the system, based on customer feedback, realizing that there are many cases in which the best running conditions, from the customer's standpoint, may fail to coincide with conditions that produce the paper having the most uniform appearance.

Returning to the two hypotheses given near the start of this article, some summary comments can be made in closing. The first hypothesis stated that papermakers need to optimize a sequence of events involving both submicroscopic and macroscopic scales of action. This statement appears to be well supported by the published literature in those cases where papermakers employ very-high-mass polyelectrolytes as retention aids. There is little doubt that both chemical and mechanical factors play a roll in determining paper's uniformity. In the absence of retention aid use, the situation probably was best summed up by Mason (1950), who stated that mechanical and hydrodynamic factors can overwhelm effects of chemical additives. That statement, however, preceded the development of modern retention aid polymers (Schiller and Suen 1956).

A second hypothesis proposed that papermakers' relative success in achieving quite favorable combinations of product uniformity, in addition to efficient retention of fine particles, is due to the fact that fibers can be detached from each other by flow events that are not sufficiently intense to dislodge fine particles from each other or from the fiber surfaces. This hypothesis was found to agree with some approximate calcula-tions, and also to be consistent with various published findings. The mechanism suggests, however, that it might be possible to develop retention aid systems that are more highly tuned in terms of providing a predictable strength of attachment between solid objects in the papermaking furnish. Such developments can be expected to make future papermakers yet more successful in their quest to retain fine particles efficiently, while producing uniform paper.

\section{REFERENCES CITED}

Adamsky, F. A., Gibbon, D. L., Simon, G. L., and Williams, R. H. (1991). "Retention mechanisms using a unique dual polymer approach," Proc. TAPPI 1991 Papermakers Conf., TAPPI Press, Atlanta, 469-479.

Adler, P. M., Takamura, K., Goldsmith, H. L., and Mason, S. G. (1981). "Particle motions in sheared suspensions. 30. Rotations of rigid and flexible dumbbells (theoretical)," J. Colloid Interface Sci. 83(2), 502-515.

Aidun, C. K. (1996). “A fundamental opportunity to improve paper forming," Tappi J. 79(6), 55-60.

Aidun, C. K. (1998). "Quantitative evaluation of the forming jet delivered from four different hydraulic headboxes using high speed digital imaging," Tappi J. 81(4), 172179.

Alince, B., and Robertson, A. A. (1974). "Aggregation of microcrystalline cellulose with polyethylenimine," Colloid Polymer Sci. 252, 920-927.

Allen, L. H., and Yaraskavitch, I. (1989). "Dual polymer retention aids - A review," TAPPI Retention and Drainage Short Course Notes, TAPPI Press, Atlanta, 59-63. 
Allen, L. H., and Yaraskavitch, I. M. (1991). "Effects of retention and drainage aids on paper machine drainage: A review," Tappi J. 74(7), 79-84.

Alfano, J. C., Carter, P. W., and Gerli, A. (1998). "Characterization of the flocculation dynamics in a papermaking system by non-imaging reflectance scanning laser microscopy (SLM)," Nordic Pulp Paper Res. J. 13(2), 159-165.

Alince, B., and Robertson, A. A. (1974). "Aggregation of microcrystalline cellulose with polyethyleneimine," Colloid Polym. Sci. 252, 920-927.

Andersson, K. and Lindgren, E. (1996). "Important properties of colloidal silica in microparticulate systems," Nordic Pulp Paper Res. J. 11(1), 15-21, 57.

Andersson, S. R., Nordstrand, T., and Rasmuson, A. (2000). "The influence of some fiber and solution properties on pulp fiber friction," J. Pulp Paper Sci. 26(2), 67-71.

Andersson, S. R., Ringnér, J., and Rasmuson, A. (1999). "The network strength of nonflocculated fiber suspensions," Nordic Pulp Paper Research J. 14(1), 61-70 (1999).

Anker, L. S. (2002). "Practical experiences in additive screening using a torque-based flocculation analyzer," Tappi J. 1(6), 3-8.

Åsselman, T., and Garnier, G. (2000). "The role of anionic microparticles in a poly (acrylamide)-montmorillonite flocculation aid system," Colloids Surf. A 170(2/3), 7990.

Åsselman, T., and Garnier, G. (2001). "The flocculation mechanism of microparticulate retention aid systems," J. Pulp Paper Sci. 27(8), 273-278.

Back, E. L., and Salmén, N. L. (1982). "Glass transitions of wood components hold implications for molding and pulping processes," Tappi 65(7), 107-110.

Baker, C. F. (1995). "Good practice for refining the types of fiber found in modern paper furnishes," Tappi J. 78(2), 147-153.

Beck, U., Müller, F., Goossens, J. W. S., Rohleff, E., and Tretter, H. (1977). "Theoretical and practical contributions to clearing up retention problems," Wochenbl. Papierfabr. 105(11/12), 391-398.

Beghello, L. (1998). "Some factors that influence fiber flocculation," Nordic Pulp Paper Res. J. 13(4), 274-279.

Beghello, L., and Eklund, D. (1997). "Some mechanisms that govern fiber flocculation," Nordic Pulp Paper Res. J. 12(2), 119-123.

Beghello, L., and Eklund, D. (1999). "The influence of the chemical environment on fiber flocculation,” J. Pulp Paper Sci. 25(7), 246-250.

Bernié, J.-P., and Douglas, W. J. M. (2001). "Effect of a wet-end additive on the components of formation of tissue," Proc. TAPPI Papermakers Conf., TAPPI Press, Atlanta, electronic document.

Bjellfors, C., Eriksson, K.-E., and Johanson, F. (1965). "Influence of cations on cellulose fiber networks," Svensk Papperstidn. 68(24), 865-869.

Björkman, U. (2003). "Break-up of suspended fiber networks," Nordic Pulp Paper Res. J. 18(1), 32-37.

Blanco, A., Fuente, E., Negro, C., Monte, M. C., and Tijero, J. (2002). "Focused beam reflectant measurement as a tool to measure flocculation," Tappi J. 1(10), 14-20.

Bliss, T. (1996). "Screening in the stock preparation system," TAPPI Stock Preparation Short Course Notes, TAPPI Press, 171-193. 
Bonfanti, J. -D., Roux, J. -C., and Rueff, M. (2000). "Hydraulic headbox S - Technology and industrial results," Wochenbl. Papierfabr. 128(20), 1372-1375.

Brenner, H. (1968). "The slow motion of a sphere through a viscous fluid towards a plane surface," Chem. Eng. Sci. 16(3-4), 242-251.

Britt, K. W. (1973). "Mechanisms of retention during paper formation," Tappi 56(10), 4650.

Britt, K. W., and Unbehend, J. E. (1976). "Mew methods of monitoring retention," Tappi 59(2), 67-70.

Buontempo, J. T., Sherman, L. M., and St. John, M. R. (1996). "Effects of salts on the performance of cationic flocculants used as retention aids for alkaline fine paper," Proc. TAPPI 1996 Papermakers Conf., TAPPI Press, Atlanta, 49-58.

Chang, M. Y., and Robertson, A. A. (1967). "Flocculation studies of fiber suspensions: Influence of zeta potential," Pulp Paper Mag. Can. 68(9), T438-T444.

Cleaver, J. W., and Yates, B. (1973). "Mechanism of detachment of colloidal particles from a flat substrate in a turbulent flow," J. Colloid Interface Sci. 44(3), 464-474.

Clemençon, I., and Gerli, A. (2000). "Effect of flocculant/microparticles retention programs on floc properties," Paper Technol. 41(8), 25-33.

Condon, M. (1996). "Mechanical aspects of forming and formation," Proc. TAPPI 1996 Papermakers Conf., TAPPI Press, Atlanta, 253-273.

Corson, S. R. (2002). "Process impacts on mechanical pulp fiber and sheet dimensions," Pulp Paper Can. 103(2), 20-27.

Das, B. S., and Lomas, H. (1973). "Flocculation of Paper Fines. I. Adsorption of and Flocculation by Polyelectrolytes. II. Study of the Nature of the Solid Surface and Soluble Impurities," Pulp Paper Mag. Can. 74(8), 95-100.

Diesen, M. (1998). Economics of the Pulp and Paper Industry, Papermaking Sci. Technol. Ser., Book 1, Fapet Oy, Helsinki, Finland.

Dodson, C. T. J. (1996). "Fiber crowding, fiber contacts, and fiber flocculation," Tappi J. 79(9), 211-216.

Dodson, C. T. J., and Serafino, L. (1993). "Flocculation, dispersion and dynamic scenarios for formation," Nordic Pulp Paper Res. J. 8(2), 264-272.

Dunham, A. J., Tubergen, K. R., Govoni, S. T., and Alfano, J. C. (2000). "The effect of dissolved and colloidal substances on flocculation of mechanical pulps," J. Pulp Paper Sci. 26(3), 95-101.

Eames, J. (1993). "Modified foil blade design improves forming table drainage, turbulence," Pulp Paper 67(4), 45-48.

Egelhof, D. (1972). "Flocculation in streaming fiber suspensions," Wochenbl. Papierfabr. 100(13), 494-499.

Eisenlauer, J., Horn, D., Linhart, F., and Hemel, R. (1987). "Fiber-optic flocculation sensor for on-line control of retention and drainage aids efficiency," Nordic Pulp Paper Res. J. 4(4), 132-138.

Ericksson, L., and Alm, B. (1993). "Effects of polyelectrolyte characteristics and flocculation conditions on fine particle floc properties," Nordic Pulp Paper Res. J. 8(1), 153-159,175.

Erspamer, A. (1940). "The flocculation and dispersion of papermaking fibers," Paper Trade J. 110(June 13), 33-38. 
Farnood, R. R., Loewen, R. R., and Dodson, C. T. J. (1993). "Forming and formation of paper," in Products of Papermaking, Proc. $10^{\text {th }}$ Fund Res. Symp., Oxford, 1993, C. F. Baker (ed.), Vol. 1, 183-208.

Farnood, R. R., Loewen, S. R., and Dodson, C. T. J. (1994). "Estimation of intra-floc forces," Appita 47(5), 391-396.

Fleer, G. J., Cohen Stuart, M. A., Scheutjens, J. M. H. M., Cosgrove, T., and Vincent, B. (1993). Polymers at Interfaces, Chapman and Hall, London.

Fleer, G. J., and Lyklema, J. (1974). "Polymer adsorption and its effect on the stability of hydrophobic colloids. II. The flocculation process as studied with the silver iodidepolyvinyl alcohol system," J. Colloid Interface Sci. 46(1), 1-12.

Forsberg, S., and Ström, G. (1994). "The effect of contact time between cationic polymers and furnish on retention and drainage," J. Pulp Paper Sci. 20(3), J71-J76.

Giri, M., Simonsen, J., and Rochefort, W. E. (2000). "Dispersion of pulp slurries using carboxymethylcellulose," Tappi J. 83(10), 58 [electronic document].

Goldman, A. J., Cox, R. G., and Brenner, H. (1967). "Slow viscous motion of a sphere parallel to a plane wall. II. Couette flow," Chem. Eng. Sci. 22(4), 653-660.

Goossens, J. W. S., and Luner, P. (1976). "Flocculation of Microcrystalline Cellulose Suspensions with Cationic Polymers: Effect of Agitation," Tappi 59(2), 89-94.

Gorres, J., Grant, R., Cresson, T., and Luner, P. (1986). "Effect of drainage on randomly formed papers: Simulation study," Tappi J. 69(7), 104-105.

Gosz, M., Nair, S., Cassel, K., and Alkhader, M. (2003). "A computational model for predicting the behavior of pulp fibers in shear-driven flows," Proc. TAPPI 2003 Spring Tech. Conf., electronic doc., TAPPI Press, Atlanta.

Gregory, J. (1973). "Rates of flocculation of latex particles by cationic polymers," $J$. Colloid Interface Sci. 42(2), 448-456.

Gregory, J. (1976). "The effect of cationic polymers on the colloidal stability of latex particles," J. Colloid Interface Sci. 55(1), 35-44.

Gregory, J., and Sheiham, I. (1974). "Kinetic aspects of flocculation of a polystyrene latex by cationic polymers," Br. Polymer J. 6(1), 47-59.

Gruber, E., Gelbrich, M., and Schempp, W. (1997). "Morphological and chemical factors affecting dewatering," Wochenbl. Papierfabr. 125(2), 66-72.

Gruber, E., and Müller, P. (2001). "Investigations of the flocculation behavior of microparticle retention systems," Proc. TAPPI 2001 Papermakers Conf., electronic doc., TAPPI Press, Atlanta.

Haslam, J. H., and Steele, F. A. (1936). "The retention of pigments in paper," Tech. Assoc. Papers 19, 249-252.

Healy, T. W., and La Mer, V. K. (1964). "The energetics of flocculation redispersion of polymers," J. Colloid Sci. 19(4), 323-332.

Hedborg, F., and Lindström, T. (1996). "Some Aspects on the Reversibility of Flocculation of Paper Stocks,” Nordic Pulp Paper Res. J. 11(4), 254-259.

Herrington, T. M., and Petzold, J. C. (1992). "An investigation into the nature of charge on the surface of papermaking woodpulps. 2. Analysis of potentiometric titration data," Colloids Surf. 64(2), 109-118.

Higashitani, K., Inada, N., and Ochi, T. (1989). "Floc breakup in contraction flow to orifice," presented at AICHE Ann. Mtg., San Francisco. 
Hinze, J. O. (1955). "Fundamentals of the hydrodynamic mechanism of splitting in dispersion processes," AIChE J. 1(3), 289-295.

Hogg, R., Healy, T. W., and Fuerstenau, D. W. (1966). "Mutual coagulation of colloidal dispersions," Trans. Faraday Soc. 62(6), 1638-1651.

Horn, D. (2001). "Exploring the nanoworld of interfaces and their functions during paper manufacturing and upgrading," Wochenbl. Papierfabr. 129(23/24), 1589-1596.

Horn, D., and Linhart, F. (1991). "Retention Aids," in Paper Chemistry, J. Roberts (ed.), Blackie, Glasgow, Chapter 4, 44-62.

Hua, X., Tanguy, P. A., Li, R., and van Wagner, J. S. (1996). "Effect of basestock formation on paper coating," Tappi J. 79(5), 112-115.

Hubbe, M. A. (1984). "Theory of detachment of colloidal particles from flat surfaces exposed to flow," Colloids Surf. 12(1-2), 151-178.

Hubbe, M. A. (1985). "Detachment of colloidal hydrous oxide spheres from flat solids exposed to flow. 2. Mechanism of release," Colloids Surf. 16(3-4), 249-270.

Hubbe, M. A. (1986). "Retention and hydrodynamic shear," Tappi J. 69(8), 116-117.

Hubbe, M. A. (1987a) "Detachment of colloidal hydrous oxide spheres from flat solids exposed to flow. 3. Forces of adhesion," Colloids Surf. 25(2-4), 311-324.

Hubbe, M.A. (1987b). "Detachment of colloidal hydrous oxide spheres from flat solids exposed to flow. 4. Effect of polyelectrolytes," Colloids Surf. 25(2-4), 325-339.

Hubbe, M. A. (2000). "Reversibility of polymer-induced fiber flocculation by shear. 1. Experimental methods," Nordic Pulp Paper Res. J. 15(5), 545-553.

Hubbe, M. A. (2001). "Reversibility of polymer-induced fiber flocculation by shear. 2. Multi-component chemical treatments," Nordic Pulp Paper Res. J. 16(4), 369-375.

Hubbe, M. A. (2002). "Fines management for increased paper machine productivity," Proc. Sci. Tech. Advan. Wet End Chem., Vienna, May 2002, Pira, Leatherhead, Surrey, UK, Paper 3.

Hubbe, M. A. (2005a). Emerging technologies in flocculation, Pira International, Leatherhead, UK.

Hubbe, M. A. (2005b). "Microparticle programs for retention and drainage," in Micro and Nanoparticles in Papermaking, J. Rodriguez (ed.), TAPPI Press, Atlanta, 2005.

Hubbe, M. A., and Rojas, O. J. (2005). "The paradox of papermaking," Chem. Eng. Education 39(2), 146-155.

Hubbe, M. A., and Wang, F. (2002). "Where to add retention aid: Issues of time and shear," Tappi. J. 1(3), 28-33.

Huber, P., Roux, J.-C., Mauret, E., Belgacem, N., and Pierre, C. (2003). "Suspension crowding for a general fiber-length distribution: Application of flocculation mixtures of short and long papermaking fibers," J. Pulp Paper Sci. 29(3), 77-85.

Hunter, D. (1947). Papermaking: The History and Technique of an Ancient Craft, $2^{\text {nd }}$ Ed., Alfred Knopf, New York.

Hunter, R. J. (1987). Foundations of Colloid Science, Clarendon Press, Oxford.

Hutton, I. M. (1995). "The concerns of forming wet lay nonwovens from long fibers," in Proc. 1995 Nonwovens Conf., TAPPI Press, Atlanta.

Islek, A. A., Parsheh, M., Yoda, M., and Aidun, C. K. (2004). "The impact of turbulence and swirl on the flow in the tube bank part of a paper mill headbox," Proc. TAPPI 2004 Spring Tech. Conf., electronic doc., TAPPI Press, Atlanta. 
Jacquelin, G. (1968). "Improvements in or relating to the method of and apparatus for treating suspensions of fibers for the formation of aggregates," UK Pat. 1,109,895.

Jokinen, O., and Ebeling, K. (1985). "Flocculation tendency of papermaking fibers," Paperi Puu 67(5), 317-325.

Jokinen, O., and Palonen, H. (1986). "Interdependence of retention and formation in the manufacture of SC paper," Paperi Puu 68(11), 801-802, 805-808.

Kaji, H., Monma, K., and Katsura, T. (1991). "Fractal analysis of flocculation in pulp suspension," Proc. TAPPI 1991 Int'l. Paper Physics Conf., TAPPI Press, Atlanta, Vol. 1, 291-297.

Kasper, D. R. (1971). "Theoretical and experimental investigations of the flocculation of charged particles in aqueous solutions by polyelectrolytes of opposite charge," Ph.D. Thesis, Cal. Inst. Technol., Pasadena.

Keith, J. M. (1994). "Dispersion of synthetic fiber for wet-lay nonwovens," Proc. 1994 Nonwovens Conf., TAPPI Press, Atlanta.

Keller, D. S., and Pawlak, J. J. (2001). " $\beta$-radiographic imaging of paper formation using storage phosphor screens," J. Pulp Paper Sci. 27(4), 117-123.

Keller, D. S., and Lucas, R. A. (2002). "The effect of forming element induced energy on the material distribution, structure, and structural properties of the paper web," Paper Technol. 43(4), 29-37.

Kerekes, R. J. (1983). "Pulp floc behavior in entry flow to constrictions," Tappi 66(1), 8891.

Kerekes, R. J. (1995). "Perspectives on fiber flocculation in papermaking," 1995 Intl. Paper Phys. Conf., TAPPI Press, Atlanta, 23-31.

Kerekes, R. J., and Schell, C. J. (1992). "Characterization of fiber flocculation regimes by a crowding factor," J. Pulp Paper Sci. 18(1), J32-J38.

Kerekes, R. J., and Schell, C. J. (1995). "Effects of fiber length and coarseness on pulp flocculation," Tappi J. 78(2), 133-139.

Kerekes, R. J., Soszynski, R. M., and Tam Doo, P. A. (1985). "The flocculation of pulp fibers," in Papermaking Raw Materials, Proc. Fundamental Res. Symp., Oxford, V. Punton (ed.), Mechan. Eng. Publ. Ltd., London, 265-310.

King, C. A., and Williams, D. G. (1975). "Cellulose fiber-to-fiber and fines-in-fiber flocculation: A dynamic comparison," IPC Tech Paper Ser. 3, Inst. Paper Sci. Technol. at Georgia Inst. Technol., Atlanta, available at http://smartech.gatech.edu/dspace/handle/1853/2896? mode=full.

Kiviranta, A., and Paulapuro, H. (1990). "Hydraulic and rectifier roll headboxes in boardmaking," Paper Technol. 31(11), 34-40.

Kiviranta, A., and Paulapuro, H. (1992). "The role of Fourdrinier table activity in the manufacture of various paper and board grades," Tappi J. 75(4), 172-185.

Kline, J. E. (1967). "The application of the Verwey-Overbeek theory to the relative sediment volume of kaolin-water dispersions," Tappi 50(12), 590-596.

Kolmogorov, A. N. (1949). "On the breakup of droplets in turbulent flow," Doklady Akad. Nauk SSSR 66(5), 825-828.

Korteoja, M., J., Lukkarinen, A., Kaski, K., and Niskanen, K. J. (1997). “Computational study of formation effects on paper strength," J. Pulp Paper Sci. 32(1), J18-J22. 
Korteoja, M. J., Salminen, L. I., Niskanen, K. J., and Alava, M. (1998). "Statistical variation of paper strength," J. Pulp Paper Sci. 24(1), 1-13.

Krogerus, B. (1993). "Dynamic flocculation studies on fiber fines and filler clay," Nordic Pulp Paper Res. J. 8(1), 135-140.

Kropholler, H. W., and Sampson, W. W. (2001). "The effect of fiber length distribution on suspension crowding," J. Pulp Paper Sci. 27(9), 301-305.

La Mer, V. K., and Healy, T. W. (1963). "Adsorption-flocculation reactions of macromolecules at the solid-liquid interface," Rev. Pure Appl. Chem. 13, 112-133.

Langley, J.G., and Litchfield, E. (1986). "Dewatering aids for paper applications," In Proc. TAPPI Papermakers Conf., TAPPI Press, Atlanta.

Lee, C. W., and Brodkey, R. S. (1987). "A visual study of pulp floc dispersion mechanisms," AIChE J. 33(2), 297-302.

Lee, P. F. W., and Lindström, T. (1989). "Effects of high molecular mass anionic polymers on paper sheet formation," Nordic Pulp Paper Res. J. 4(4), 61-70.

Li, T.-Q., and Ödberg, L. (1997). "Studies of flocculation in cellulose fiber suspensions by NMR imaging," J. Pulp Paper Sci. 23(8), J401-J405.

Li, T.-Q., Ödberg, L., Powell, R. L., Weldon, M., and McCarthy, M. J. (1995). "Quantitative measurements of flow acceleration by means of nuclear magnetic resonance imaging," Nordic Pulp Paper Res. J. 10(2), 133-138.

Lindström, T. (1989). "Some fundamental chemical aspects on paper forming." in Fundamentals of Papermaking, C. F. Baker and V. W. Punton (eds.), Trans. $9^{\text {th }}$ Fund. Res. Symp., Cambridge, Mech. Eng. Publ., Ltd., London, 311-412.

Lindström, T., and Glad-Nordmark, G. (1984). "Flocculation of latex and cellulose dispersions by means of transient polymer networks," Colloids Surf. 8(4), 337-351.

Lindström, T., Söremark, C., and Eklund, L. (1977). "Kinetic aspects of the flocculation of cellulosic fiber dispersions with polyacrylamides," Tech. Trans. CPPA 3(4), TR114-TR118.

Linhart, F., Horn, D., Eisenlauer, J., and Hemel, R. (1987). "Monitoring and control of formation by means of a fiber optic flocculation sensor," Wochenbl. Papierfabr. 115(8), 331-338.

Liu, S. X., and Glasgow, L. A. (1997). "Aggregate disintegration in turbulent jets," Water Air Solid Pollution 95(1-4), 257-275.

Lloyd, J. A., and Horne, C. W. (1993). "The determination of fiber charge and acidic groups of radiata pine pulps," Nordic Pulp Paper Res. J. 8(1), 48-52.

Manson, D. W. (1996). "The practical aspects of formation," Wet End Operations Short Course Notes, TAPPI Press, Atlanta.

Marton, J. (1974). "Fines and wet end chemistry," Tappi J. 57(12), 90-93.

Mason, S. G. (1950). "The flocculation of pulp suspensions and the formation of paper," Tappi 33(9), 440-444.

Mason, S. G. (1954). "Fiber motions and flocculation," Tappi 37(11), 494-501.

McDonald, D., Miles, K., and Amiri, R. (2004). "The nature of the mechanical pulping process," Pulp Paper Can. 105(8), T181-T186.

McKenzie, A. W. (1968). "Structure and properties of paper. XVIII. The retention of wetend additives," Appita 21(4), 104-116. 
McNeal, M. R., Nanko, H., and Hubbe, M. A. (2005). "Imaging of macromolecular events occurring during the manufacture of paper," Proc. XIII Fundamental Research Symposium, Cambridge, Pira International, Leatherhead, Surrey, UK.

Meyer, R., and Wahren, D. (1964). "On the elastic properties of three-dimensional fiber networks," Svensk Papperstidn. 67(10), 432-436.

Nazhad, M. M., Harris, E. J., Dodson, C. T. J., and Kerekes, R. J. (2000). "The influence of formation on tensile strength of paper made from mechanical pulps," Tappi J. 83(112), 63 [electronic document].

Nguyen, T. Q., and Kausch, H.-H. (1992). "Chain extension and degradation in convergent flow," Polymer 33(12), 2611-2621.

Norman, B. (2000). "Web forming," in Papermaking Part 1: Stock Preparation and Wet End, H. Paulapuro (ed.), Fapet Oy, Helsinki, Ch. 6, 191-250.

Norman, B., Sjödin, Y., Alm, B., Björklund, K., Nilsson, F., and Pfister, J.-L. (1995). "The effect of localized dewatering on paper formation," 1995 Int'l. Paper Physics Conf., 5559.

Norman, B., and Wahren, D. (1972). "A comprehensive method for the description of mass distribution in sheet and flocculation in turbulence in suspension," Svensk Papperstidn. 75(20), 807-818.

Ny, C. L., and Messmer, M. (2004). "Potential of refining and dispersing to develop recycled fiber properties," Research Forum on Recycling Proc, $7^{\text {th }}$, TAPPI Press, Atlanta, 189-196.

O'Neill, M. E. (1968). "A sphere in contact with a plane in a slow linear shear flow," Chem. Eng. Sci. 23(11), 1293-1298.

Orts, W. J., Godbout, L., Marchessault, R. H., et al. (1995). "Shear-induced alignment of liquid-crystalline suspensions of cellulose microfibrils," ACS Symp. Ser. 597: 335348.

Paavilainen, L. (1993). "Conformability - flexibility and collapsibility - of sulfate pulp fibers," Paperi Puu 75(9-10), 689-702.

Pandya, J. D., and Spielman, L. A. (1982). "Floc breakage in agitated suspensions: Theory and data processing strategy," J. Colloid Interface Sci. 92(2), 517-531.

Parker, J. D. (1972). The Sheet Forming Process, TAPPI STAP Ser. 9, TAPPI Press, New York.

Pelton, R. (1993). "A model of the external surface of wood pulp fibers," Nordic Pulp Paper Res. J. 8(1), 113-119.

Peters, C. E. (1997). "Formation: Questions most often asked by papermakers," Proc. TAPPI 1997 Eng. Papermakers Conf., TAPPI Press, Atlanta, 103-107.

Peterson, D. E. (1994). "Nuclear density consistency meter evaluation," Proc. TAPPI 1994 Process Control Symp., TAPPI Press, Atlanta, 9-18.

Petzold, G., Buchhammer, H.-M., and Lunkwitz, K. (1996). "The use of oppositely charged polyelectrolytes as flocculants and retention aids," Colloids Surf. A. 119(1), 87-92.

Petzold, G. (1999). "Dual-addition schemes," in Colloid-Polymer Interactions: From Fundaments to Practice, R. S. Farinato and P. L. Dubin (Eds.), Wiley, New York, Ch. 3, 83-100. 
Pfau, A., Schrepp, W., and Horn, D. (1999). "Detection of a single molecule adsorption structure of poly(ethylenimine) macromolecules by AFM," Langmuir 15(9), 32193225 (1999).

Praast, H., Göttsching, L., and Wehrle, J. (1998). "Floc orientation in paper," Papier 57(6), 376-384.

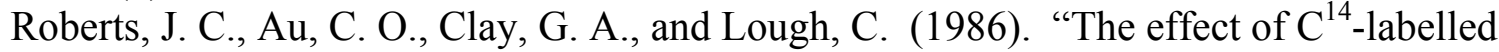
cationic and native starches on dry strength and formation," Tappi J. 69(10), 88-93.

Roberts, J. C., Au, C. O., Clay, G. A., and Lough, C. (1987). "Study of the effect of cationic starch on dry strength and formation using carbon-14 labeling," J. Pulp Paper Sci. 13(1), J1-J5.

Rojas, O. J., and Hubbe, M. A. (2004). "The dispersion science of papermaking," J. Dispersion Sci. Technol. 25(6), 713-732.

Ross, R. F., and Klingenberg, D. J. (1998). "Simulation of flowing wood fiber suspensions," J. Pulp Paper Sci. 24(12), 388-392.

Salmén, L., Kolseth, P., and de Ruvo, A. (1985). "Modeling the softening behavior of wood fibers," J. Pulp Paper Sci. 11(4), J102-J107.

Sampson, W. W. (1997). “The interdependence of sheet structure and drainage," Paper Technol. Ind. 38(8), 45-50.

Sampson, W. W., McAlpin, J., Kropholler, H. W., and Dodson, C. T. J. (1995). "Hydrodynamic smoothing in the sheet forming process," J. Pulp Paper Sci. 21(12), J422-J426.

Sandell, L. S., and Luner, P. (1974). "Flocculation of microcrystalline cellulose with cationic ionene polymers," J. Appl. Polymer Sci. 18(7), 2075-2083.

Savolainen, R. M. (1996). "The effects of temperature, $\mathrm{pH}$, and alkalinity on ASA sizing in alkaline papermaking," Proc. TAPPI 1996 Papermakers Conf., TAPPI Press, Atlanta, 289-295.

Schiher, S. C., and Getman, D. L. (1994). "Forming pulse effects on papermaking," Proc. TAPPI 1994 Wet-End Operations Short Course, 109-126, TAPPI Press, Atlanta.

Schiller, A. M., and Suen, T. (1956). "Ionic derivatives of polyacrylamide," Ind. Eng. Chem. 48(12), 2132-2137.

Schmid, C. F., and Klingenberg, D. L. (2002). "Properties and fiber flocs with frictional and attractive interfiber forces," J. Colloid Interface Sci. 226(1), 136-144.

Shah, P. N. (2000). "The role of turbulent elongational stresses on deflocculation in paper sheet formation," Tappi J. 83(4), 1-8.

Sikora, M. D., and Stratton, R. A. (1981). "The shear stability of flocculated colloids," Tappi 64(11), 97-101.

Söderberg, L. D., and Alfredsson, P. H. (1997). "Experiments concerning the creation of streaky structures inside a plane water jet," Proc. TAPPI 1997 Engineering and Paper Conf., TAPPI Press, Atlanta, 1205-1221.

Solberg, D., and Wågberg, L. (2003). "On the mechanism of cationic-polyacrylamideinduced flocculation and re-dispersion of a pulp fiber dispersion," Nordic Pulp Paper Res. J. 18(1), 51-55.

Södergren, O. F., and Neun, J. A. (2000). "Developments in activity generation on Fourdriniers," Tappi J. 83(10), 62 [electronic document]. 
Spicer, P. T., and Pratsinis, S. E. (1996). "Shear-induced flocculation: The evolution of floc structure and the shape of the size distribution at steady state," Water Res. 30(5), 1049-1056.

Smook, G. A. (1992). Handbook for Pulp and Paper Technologists, $2^{\text {nd }}$ Ed., Angus Wilde, Vancouver.

Stoere, P., Nazhad, M., and Kerekes, R. J. (2001). "An experimental study of the effect of refining on paper formation," Tappi J. 84(7), electronic document.

Stover, C. A., Koch, D. L., and Cohen, C. (1992). "Observation of fiber orientation in simple shear flow of semi-dilute suspensions," J. Fluid Mech. 238, 277-296.

Stratton, R. A. (1983). "Effect of agitation on polymer additives," Tappi J. 66(3), 141144.

Stratton, R. A., and Swanson, J. W. (1981). "Electrokinetics in papermaking: A position paper," Tappi 64(1), 79-83.

Svensson, O., and Österberg, L. (1965). "The function of wet suction boxes," Svensk Papperstidn. 68(11), 403-418.

Swanson, J. W. (1950). "The effects of natural beater additives on papermaking fibers," Tappi 33(9), 451-462.

Swerin, A. (1998). "Rheological properties of cellulosic fiber suspensions flocculated by cationic polyacrylamides," Colloids Surf. 133(3), 279-294.

Swerin, A., Glad-Nordmark, G., and Ödberg, L. (1997). "Adsorption and flocculation in suspensions by two cationic polymers - Simultaneous and sequential addition," $J$. Pulp Paper Sci. 23(8), J389-J393.

Swerin, A., and Mähler, A. (1996). "Formation, retention, and drainage of a fine paper stock during twin-wire roll-blade forming. Implications of fiber network," Nordic Pulp Paper Res. J. 11(1), 36-42.

Swerin, A., and Ödberg, L. (1993). "Flocculation and floc strength in suspensions flocculated by retention aids," Nordic Pulp Paper Res. J. 8(1), 141-147.

Swerin, A., and Ödberg, L. (1996). "Flocculation and floc strength - From the laboratory to the FEX paper machine," Papier 50(10A), V45-V47.

Swerin, A., and Ödberg, L. (1997). "Some aspects of retention aids," in The Fundamentals of Papermaking Materials, C. F. Baker (ed.), Pira Intl., Leatherhead, UK, 265-350.

Swerin, A., Ödberg, L., and Wågberg, L. (1996b). “An extended model for the estimation of flocculation efficiency factors in multicomponent flocculation systems," Colloids Surf. 113(1-2), 25-38.

Swerin, A., Powell, R. L., and Ödberg, L. (1992). "Linear and nonlinear dynamic viscoelasticity of pulp suspensions," Nordic Pulp Paper Res. J. 7(3), 126-132,143.

Swerin, A., Risinger, G., and Ödberg, L. (1996a). "Shear strength in papermaking suspensions flocculated by retention aid systems," Nordic Pulp Paper Res. J. 11(1), 30-35.

Swerin, A., Risinger, G., and Ödberg, L. (1997). "Flocculation in suspensions of microcrystalline cellulose by microparticle retention aid systems," J. Pulp Paper Sci. 23(8), J374-J381. 
Swerin, A., Sjödin, U., and Ödberg, L. (1993). "Flocculation of cellulosic fiber suspension by model microparticulate retention aid systems: Effect of polymer charge density and type of microparticle," Nordic Pulp Paper Res. J. 8(4), 389-398.

Takamura, K., Adler, P. M., Goldsmith, H. L., and Mason, S. G. (1981). "Particle motions in sheared suspensions. 31. Rotations of rigid and flexible dumbbells (experimental)," J. Colloid Interface Sci. 83(2), 516-530.

Tam Doo, P. A., and Kerekes, R. J. (1982). "The flexibility of wet pulp fibers," Pulp Paper Can. 83(2), T37-T41.

Tam Doo, P. A., Kerekes, R. J., and Pelton, R. H. (1984). "Estimates of maximum hydrodynamic shear stresses on fiber surfaces in papermaking," J. Pulp Paper Sci. 10(7), J80-J88.

Tanaka, H., Swerin, A., and Ödberg, L. (1993). "Transfer of cationic retention aid from fibers to fine particles and cleavage of polymer chains under wet-end papermaking conditions," Tappi J. 76(5), 157-163.

Tripattharanan, T., Hubbe, M.A., Venditti, R.A., and Heitmann, J.A. (2004a). "Effect of idealized flow conditions on retention aid performance. 1. Cationic acrylamide copolymer," Appita J. 57(5), 404-410.

Tripattharanan, T., Hubbe, M. A., Heitmann, J. A., and Venditti, R. A. (2004b). "Effect of idealized flow conditions on retention aid performance. Part 2: Polymer bridging, charged patches, and charge neutralization," Appita J. 57(6), 448-454.

Ulmar, M., and Norman, B. (1997). "Observations of fiber orientation in a headbox nozzle at low consistency," Proc. TAPPI 1997 Engineering and Paper Conf., TAPPI Press, Atlanta, 865-873.

Unbehend, J. E. (1976). "Mechanisms of 'soft' and 'hard' floc formation in dynamic retention measurement," Tappi 59(10), 74-77.

Van de Ven, T. G. M. (1984). "Theoretical aspects of drainage and retention of small particles on the Fourdrinier," Pulp Paper Can. 85(3), T58-T63.

Van de Ven, T. G. M., and Mason, S. G. (1981). "Comparison of hydrodynamic and colloidal forces in paper machine headboxes," Tappi 64(9), 171-175.

Wågberg, L. (2000). "Polyelectrolyte adsorption onto cellulose fibers - A review," Nordic Pulp Paper Res. J. 15(5), 586-597.

Wågberg, L., Björklund, M., Åsell, I., and Swerin, A. (1996). "On the mechanism of flocculation by microparticle retention-aid system," Tappi J. 79(6), 157-164.

Wågberg, L., and Lindström, T. (1987a). "Some fundamental aspects of dual-component retention aid systems," Nordic Pulp Paper Res. J. 2(2), 49-55.

Wågberg, L., and Lindström, T. (1987b). "Flocculation of cellulosic fibers by cationic poly-acrylamides with different charge densities," Nordic Pulp Paper Res. J. 2(4), 152-160.

Wågberg, L., and Ödberg, L. (1991). "The action of cationic polyelectrolytes used for the fixation of dissolved and colloidal substances," Nordic Pulp Paper Res. J. 6(3), 127-135.

Wagle, D. G., Lee, C. W., and Brodkey, R. S. (1988). "Further comments on a visual study of pulp floc dispersion mechanisms," Tappi J. 71(8), 137-141.

Walkush, J. C., and Williams, D. G. (1974). "The coagulation of cellulose pulp fibers and fines as a mechanism of retention," Tappi 57(1), 112-116. 
Walser, R., Eames, J. D., and Clark, W. M. (1970). "Performance analysis of hydrofoils with blades of various widths," Pulp Paper Mag. Can. 71(8), T183-T187.

Wasser, R. B. (1978). "Formation aids for paper: An evaluation of chemical additives for dispersing long-fibered pulps," Tappi 61(11), 115-118.

Waterhouse, J. F. (1993). "Effect of papermaking variables on formation," Tappi J. 76(9), 129-134.

Wikström, T., and Rasmuson, A. (1998). "Yield stress of pulp suspensions. The influence of fiber properties and processing conditions," Nordic Pulp Paper Res. J. 13(3), 243-250.

Yeung, A., Gibbs, A., and Pelton, R. (1997). "Effect of shear on the strength of polymer-induced flocs," J. Colloid Interface Sci. 196(1), 113-115.

Zauscher, S., and Klingenberg, D. J. (2000). "Surface and friction forces between cellulose surfaces measured with colloidal probe microscopy," Nordic Pulp Paper Res. J. 15(5), 459-468.

Zauscher, S., and Klingenberg, D. J. (2001). "Friction between cellulose surfaces measured with colloidal probe microscopy," Colloids Surf. A 178(1-3), 213-229. 